\title{
Fifteen years of research in innovative heating, ventilation and air conditioning plants at the Department of Management and Engineering (University of Padova)
}

\author{
Giacomo Bagarella ${ }^{1}$, Filippo Busato ${ }^{2}$, Francesco Castellotti $^{3}$, Andrea D'Ascanio ${ }^{4}$, Renato \\ Lazzarin $^{5 *}$, Fabio Minchio ${ }^{6}$, Daniele Nardotto ${ }^{7}$, Marco Noro $^{5, \dagger}$, and Lorenzo Zamboni ${ }^{8}$ \\ ${ }^{1}$ Aermec S.p.A., 37040 Bevilacqua, Italy \\ ${ }^{2}$ Economy Department, Università Mercatorum, 00186 Roma, Italy \\ ${ }^{3} 3 \mathrm{~F}$ Engineering, 37100 Verona, Italy \\ ${ }^{4}$ Sinergia S.C., 36100 Vicenza, Italy \\ ${ }^{5}$ Department of Management and Engineering (DTG), University of Padova, 36100 Vicenza, Italy \\ ${ }^{6} 3 \mathrm{~F}$ Engineering, 36051 Creazzo, Italy \\ ${ }^{7}$ E-skin S.r.l., 36100 Vicenza, Italy \\ ${ }^{8}$ Stefani S.p.A., 36020 Castegnero, Italy
}

\begin{abstract}
At the Department of Management and Engineering (DTG) of the University of Padova (Italy), the research team led by Prof. Renato Lazzarin, formed by the authors, worked during the first fifteen years of the millennium on different topics focused on innovative heating, ventilation and air conditioning technologies. Both experimental and theoretical/modelling studies were carried out: an air conditioning system with liquid desiccant operating for annual climatization was designed, realized, and tested; a self-regenerating liquid desiccant cooling system based on an electric heat pump was installed and monitored in a new building of the Vicenza Hospital for dehumidification, heating and cooling; a gas engine heat pump plant for the air conditioning of a building of the DTG was designed, realized, and monitored for a long period; a multisource heat pump plant was modelled and dynamically simulated, and then realized and monitored for the climatization of a school building; hybrid water/phase change materials tanks were modelled, designed and tested for thermal energy storage; finally, thermal and electric solar cooling plants were modelled and dynamically simulated for evaluating energy performance. The paper highlights the main theoretical and experimental approaches and the results of the research during the fifteen-year period.
\end{abstract}

\section{Introduction}

\footnotetext{
${ }^{*}$ Retired in 2018

† Corresponding author: marco.noro@unipd.it
} 
Today, the energy needs for space cooling and heating of buildings amount to $30-45 \%$ of the total demand, with the percentage depending on the specific country [1]. The importance of achieving energy efficiency has increased over time, as it is now re-ported in many international directives, such as the Energy Performance of Buildings Directive (EPBD) (new and highly retrofitted buildings have to be nearly zero energy since 2021 [2]), the Energy Efficiency Directive [3], and the European Green Deal (greenhouse gas emissions must be reduced to reach carbon neutrality by 2050 [4]).

Even if new and refurbished buildings feature low heat losses due to an extensive application of thermal insulation, the heating requirement is still high in existing buildings (the highest quota), particularly in temperate zones [5]. On the other hand, the demand for cooling energy is increasing, especially in milder climates, due to global climate change, and the reduced capacity of more insulated buildings to waste energy [6]. For example, Ukey and Rai [7] investigated the impact of global warming on energy requirements for space cooling in eight major Indian cities. Using the outputs of the general circulation model and historical weather records, they calculated that the cooling degree days, and therefore the cooling requirements, will increase by $2.9-22.9 \%$ in the 2020 s and by $8.3-$ $54.1 \%$ in the $2050 \mathrm{~s}$.

In recent decades, more efficient heating and cooling systems have become desirable to reduce the energy demand of fossil fuels or electricity: condensing boilers, heat pumps, open and closed cycle sorption systems, solar cooling by thermal and electrical technologies [8]. Professor Lazzarin worked on such subjects during all his academic life since the late 1970s. During half of this life, from 1990 till 2019 when he retired, he worked at the Department of Management and Engineering (DTG) of the University of Padova. Many research studies on innovative heating, ventilation and air conditioning (HVAC) plants and equipment were carried out in collaboration with his research group, the authors of this paper, during the 2000-2015 period. As the main originality of this paper, the following sections propose to go through a long period of work from a research group of a university department, describing many different technologies, configurations, and control schemes in the topic of innovative and efficient HVAC systems.

A first technology on which Professor Lazzarin has worked since the 1980s was the chemical dehumidification of air [9-14]. This technology allows many advantages in summer air conditioning: the energy post-heating process can be avoided [15], a higher temperature of the cooling water temperature can be used (which means a higher energy efficiency ratio (EER) of the chiller [16]), and the electric power of the chiller can be lowered as only the sensible cooling load must be satisfied, while the la-tent load is faced by the input of thermal energy [17]. Moreover, a reduction of the bacterial charge can be obtained by treating the air by a liquid desiccant. The work of Professor Lazzarin's group on this topic is described in Sections 2.1 and 2.2.

Most of Prof. Lazzarin's research work during his academic life was related to heat pump technology. In particular, he focused mainly on two lines: Gas Engine Heat Pump (GEHP, that is, a heat pump whose mechanical compressor is moved by an endothermic engine [18-20]) and multisource heat pump (that is, a heat pump that uses more than a single heat source). Many authors have worked on GEHP during the last decades as it is a very interesting technology because there are no losses related to electricity production and transport, and the heat from the combustion engine can be usefully recovered. Many references can be found in Hepbasli et al. [21], which gave a brief outline of the historical development and a review of such systems for residential and industrial applications in terms of energy and exergy analysis. More recently, Roselli et al. [22] presented a comprehensive review of this technology in the air conditioning and the future role in the decarbonization of the energy sector. The work of Prof. Lazzarin described in Section 2.3 is focused on the full energy and economic analysis of a monitored real case GEHP plant. 
The second line of research (multisource heat pump) was interesting in the view of Prof. Lazzarin considering the drawbacks of the outside air (the most common heat source of a heat pump due to its (apparent) gratuitousness). The first is the energy cost of its movement; the second is its temperature that decreases when the thermal load of the building increases, determining the decrease in the coefficient of performance (COP) and thermal capacity. For these reasons, multisource heat pumps (i.e., the main cold source is supported by one or more others) have been gaining attention during the last decades. For example, Xu and Zhang [23] described a solar air source heat pump for domestic water heating with a specially designed flat-plate collector/evaporator; the influence of compressor capacity, ambient temperature, and solar radiation on performance were analysed. In [24], the energy performance of the series and parallel configurations of a new solar-air multisource heat pump were described. Emmi et al. [25-26] investigated the energy performance of a multisource heat pump plant for space heating and domestic hot water (DHW) of a single-family house in the north-east of Italy. The plant was combined with photovoltaic thermal hybrid solar collectors $(\mathrm{PV} / \mathrm{T})$, giving an annual COP equal to 3.64. A very recent review on multi-source heat pumps is reported in [27]. In Section 2.4, the research work of the authors concerning the design, monitoring and data analysis of the multisource absorption heat pump plant of a new school building in the town of Agordo (North Italy) is reported.

In the second part of the 2000-2015 period, the interest of Professor Lazzarin and his research group also extended to the use of phase change materials (PCM) in solar heating and cooling plants as thermal energy storage (TES). They are materials that melt (loading phase) and solidify (unloading phase) over a fairly narrow temperature range, that is, the characteristic operating temperature of the TES. They allow some advantages with respect to sensible (water) TES: a greater utilization of the solar radiation for heating/cooling demands for a given volume of TES, or a smaller size of TES for a given solar fraction. For such reasons, PCMs have been gaining increasingly attention during the last few decades. Que et al. [28] recently discussed the issues specifically related to phase change hysteresis and supercooling phenomena during the phase transition of the PCM. In [29], an updated review on the performance, applications, and key challenges of inorganic PCM in the building sector is presented. Mousavi et al. [30] recently proposed a review on the operating characteristics of various types of PCM embedded radiant chilled ceiling, highlighting both positive potentials (energy savings, peak load shifting, and thermal comfort) and some criticisms (careful selection of the system design and operating variables to assure high energy performance). At the end of the first decade of 2000, most studies concerned theoretical simulations, and none focused on the economic and energy optimization of a real solar cooling and heating plant with PCM compared to sensible heat storage. This comparison is de-scribed in Section 2.5.

A final line of research in innovative HVAC plants followed by Professor Lazzarin was related to solar cooling. Figure 1 shows the main alternatives to convert solar energy into cooling by thermodynamic cycles. Solar electric (photovoltaic, PV) and thermal are the main options. Professor Lazzarin has worked on solar cooling since the late 1970s. During the first decades, the main interest was focused on thermal solar cooling due to the high cost of PV. Therefore, solar thermal collectors have been widely developed, increasing their efficiency and reliability and decreasing cost. Nevertheless, the cost of photovoltaic energy has had a continuous reduction with an increasing velocity from the second part of the first decade of 2000. To get an idea, the cost per peak watt was 76 USD in 1977, 5 USD in 2008, but around 0.20 USD in 2020 [31]. 


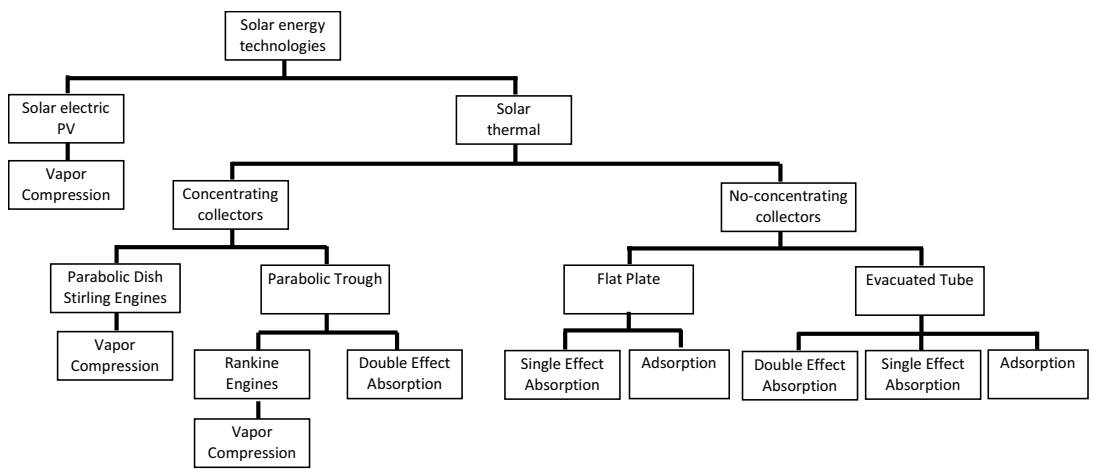

Fig. 1. Alternatives of solar energy into cooling effect.

Recently, many authors proposed some review of the literature on solar cooling. For example, Chauhan et al. [32] provided an updated review on the status of adsorption refrigeration. They investigated the effects of working parameters (regeneration, condenser and evaporator temperatures, cycle time, and interstage pressure) on specific cooling power and EER, both by experimental and theoretical research work. In [33], a more general review on the technologies available to convert solar energy into cooling, heating and electricity was reported, proposing an analysis from an efficiency, economic and environmental perspective. Alobaid et al. [34] reported an extended review on experimental and computational studies on efficiencies and performance indicators of photovoltaic thermal absorption cooling systems. In such a context, in 2014 the authors carried out a study comparing the competitiveness of the different solar cooling technologies on the basis of energy performance, economic specific investment cost, and economic profitability. The results are reported in Section 2.6.

In the following sections, the main hypotheses, methods, and results of the previously described research studies are synthesized. Finally, some conclusions are reported as a synthesis of the different research works on innovative HVAC technologies carried out in fifteen years by the authors at the Department of Management and Engineering.

\section{Research in HVAC at DTG: main results and discussion}

In the next sections, the main research work on innovative HVAC technologies carried out by the authors in different periods during the 2000-2015 period is described. Both experimental and theoretical/modelling studies were developed under the supervision of Professor Lazzarin.

\subsection{Open-cycle liquid desiccant system: a real case for air conditioning of a university building}

Professor Lazzarin and members of his research team designed, at the end of the 1990s, a liquid desiccant-based air conditioning plant for the annual climatization of one of the renovated buildings of the DTG [35]. Two thermal zones of the building (whole volume $14,500 \mathrm{~m}^{3}$ ), that is, zone A - refectory - and zone B - main lecture hall - featured high latent load due to the high presence of people, and an important ventilation volume rate for the necessary air changes. Each zone was served by an innovative air handling unit (AHU) set 
up with an absorption tower for the chemical dehumidification (by a LiBr-water liquid desiccant) of the treated air.

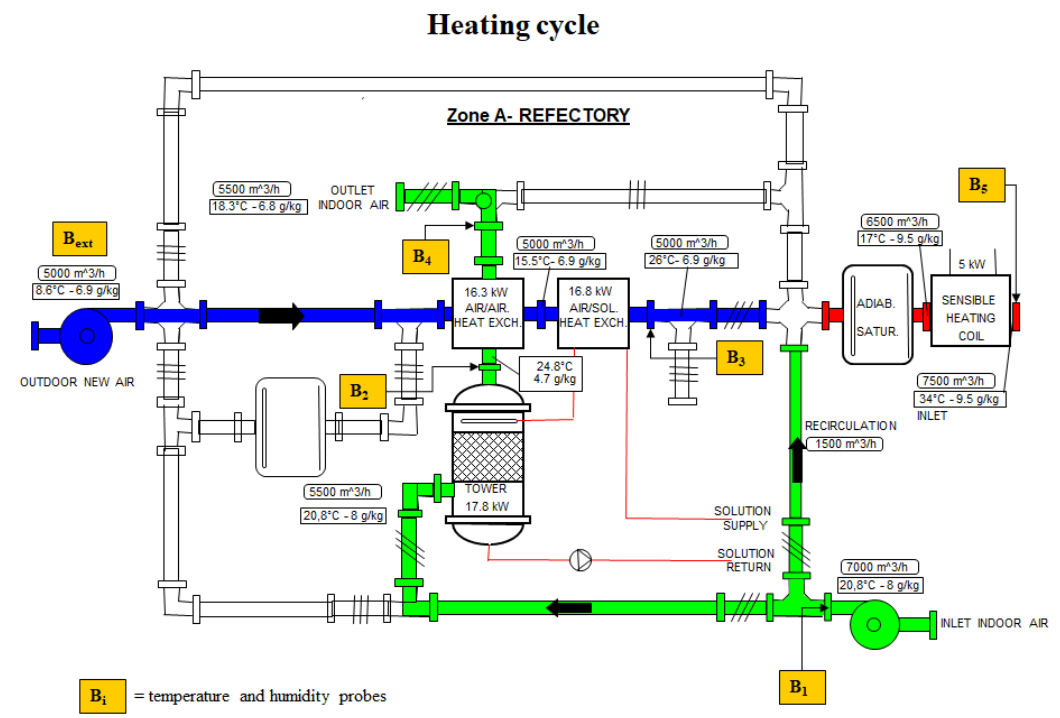

Fig. 2. A-zone (refectory) during winter heating operation mode.

Despite some undervalued difficulties that had forced the stop for some months during the first running period, the plant was carefully monitored during the first years of 2000 . Some operational periods allowed to monitor and log many data (temperature, flow rate, state of the equipment) and develop a comprehensive energy analysis of the entire plant [35].

In winter heating, the system operated as an open-cycle absorption heat pump. As a cold source, it used both latent and sensible quota of the heat of exhausted air (Figure 2). The latent heat was recovered by a condenser that condensed the vapor released by the regenerator. The latter was a suitable heat exchanger operating at less than atmospheric pressure and supplied by pressurized water (produced by a natural gas boiler). The sensible heat of exhausted air was recovered by an air/air heat exchanger to preheat the fresh air. The latter was further heated by a solution-to-air heat exchanger. The preheating of the fresh air and the heat exchange with the diluted solution by a solution-to-solution heat exchanger were essential as they lowered the temperature of solution, making the dehumidification process more effective.

A winter test during some days of operation allowed to highlight some malfunctions of the plant. An average dehumidification of $1.2-1.5 \mathrm{~g}_{\mathrm{v}} / \mathrm{kg}_{\text {air }}$ obtained by the packed column of the refectory AHU was measured. It was a lower value than expected. Furthermore, sometimes the exhausted air was humidified: this was due to the lower value of the $\mathrm{LiBr}$ concentration in the water solution compared to the design value (less than $50 \%$ instead of $52 \%$ ). The reasons were due to the difficulty to supply the solution in the correct quantity as many litres were leaked for some damages to the gaskets in not inspectable parts of the line. Furthermore, an average temperature of the solution at the entrance of the tower higher than the design value (for example, $35{ }^{\circ} \mathrm{C}$ instead of $25{ }^{\circ} \mathrm{C}$ ) strongly reduced the dehumidification capacity of the solution. Moreover, some solution tended to bypass the air as it filled the spaces near the wall of the packet column [36]. Figure 3 reports the energy 
balance of the solution during operation of zone A (refectory) to determine the sharing of the energy input. Figure 4 shows the energy balance of the air side to analyse the different components of the thermal load of the conditioned room.

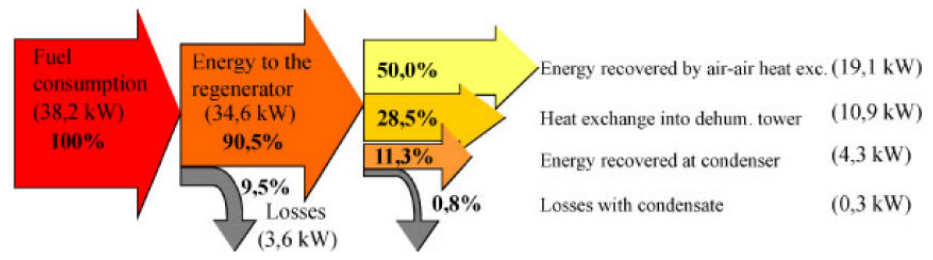

Fig. 3. Energy balance of the solution in winter mode (zone A, refectory).

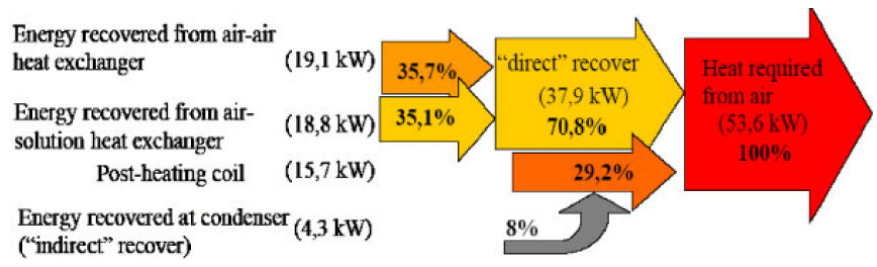

Fig. 4. Air energy balance in winter mode (zone A - refectory).

The greater part of the energy in input to the regeneration boiler $(38 \mathrm{~kW})$ was directed to the heat exchange in the dehumidifying column (about 28\%) and, above all, to the preheating of the fresh air (about 50\%). The heat recovered by the condenser was similar to energy content of the vapour from the exhaust $(4.3 \mathrm{~kW}, 11 \%)$, lower than predicted (Figure 3).

From the air-side point of view, the energy requirement by zone A was about $54 \mathrm{~kW}$. Apparently, the traditional heating system provided only the quota of $29 \%$, whereas the innovative system provided the largest part (71\%, obtained by the solution-to-air and air-toair heat exchangers). However, the quota provided by the innovative system was higher $(79 \%)$ as a fraction $(29 \%)$ was due to the heat recovery of the condenser, instead to be provided by the traditional heating system (Figure 4). In the event of a stronger dehumidification, a greater contribution would be provided. The primary energy ratio (PER) obtained was 1.11, less than expected (1.3) for the above-mentioned reasons.

In the summer cooling operation, the packed column provided dehumidification to a part of the recirculated air. The latter passed successively in an air-to-air heat exchanger to be cooled by exhausted air, then mixed with fresh air, and finally cooled to the required conditions by a cooling coil (Figure 5). Like in winter operation, a solution-to-air heat exchanger provided to cool the liquid desiccant by the exhausted air (mixed with external air precooled by an adiabatic saturator) before entering the packed column. 


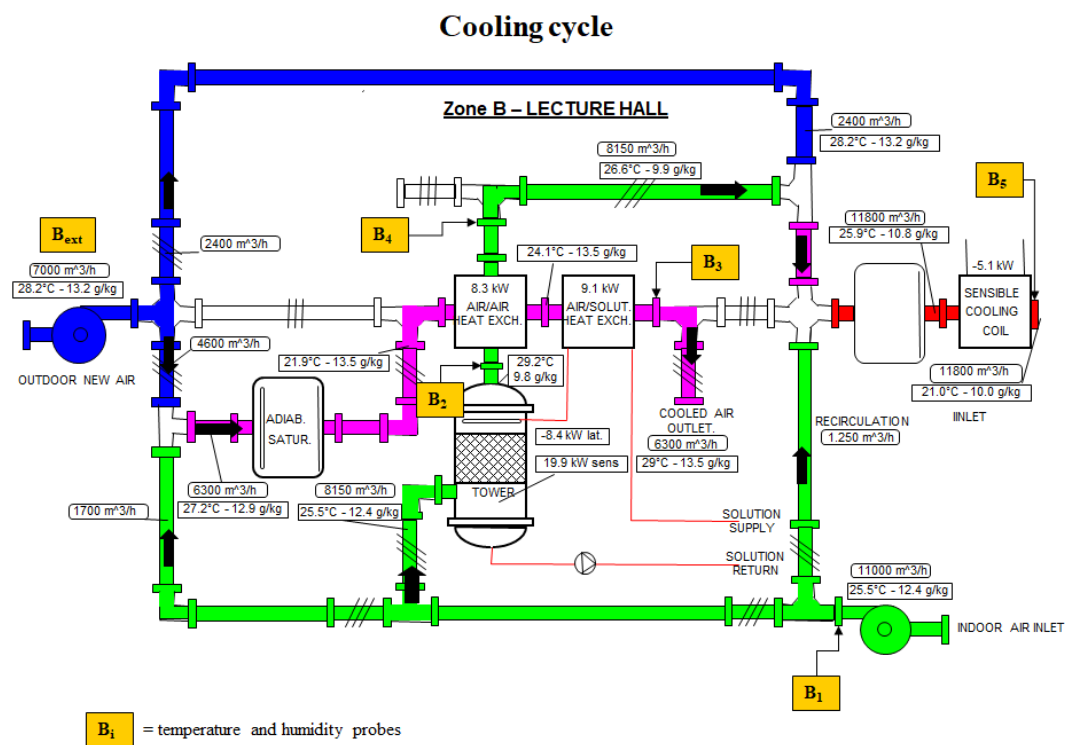

Fig. 5. Zone B (main lecture hall) during summer cooling operation mode.

As the main advantage of the innovative system during summer operation, indoor air humidity could be controlled without the need to cool below the dew point temperature. This was tested even with peaks of latent loads, for example, at the opening of the refectory with contemporaneous cooking and high presence of people. Similarly to the winter mode, the average dehumidification measured during the tests was lower than expected (from 1.5 to $3 \mathrm{~g}_{\mathrm{v}} / \mathrm{kg}_{\mathrm{air}}$ ).

The energy balance of the solution regeneration process (Figure 6) showed that the 49 $\mathrm{kW}$ of input energy from fuel was shared among the cooling tower (to cool the condenser, $26 \%$ ), the solution cooling coil (29\%) and the packed column (17 kW, about $35 \%)$. Thermal energy available at a temperature around $50{ }^{\circ} \mathrm{C}$ by the condenser and the solution cooling coil could have been usefully dedicated to applications needing heat even in summer (swimming pools, hospitals, refectories); that would have greatly improved the system performance.

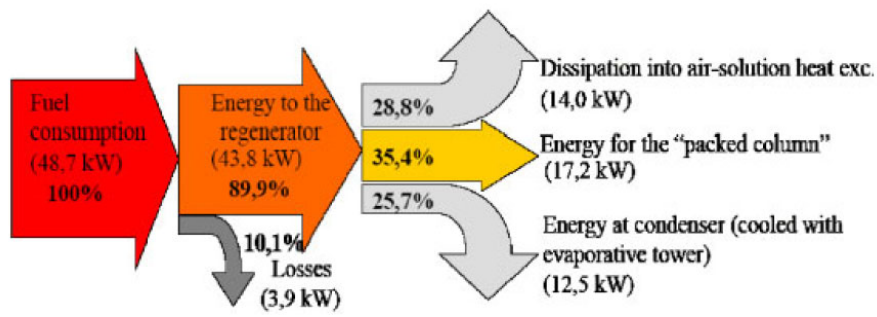

Fig. 6. Energy balance of solution in summer mode, main lecture hall. 


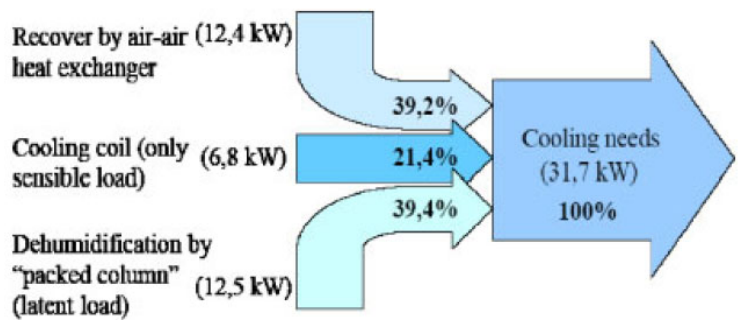

Fig. 7. Air energy balance in summer mode, main lecture hall.

Figure 7 shows the energy balance of air: the air-to-air heat exchanger and the traditional cooling coil (21\%) allowed to satisfy the sensible needs (19 kW, about $60 \%)$. Instead, chemical dehumidification fully satisfied the latent load $(12.5 \mathrm{~kW}$, approximately $40 \%$ ). The primary energy ratio of the system resulted in 0.51 during the summer surveyed period.

As a further improvement of this value, the adiabatic humidification of the exhaust air could be proposed: the AHU was provided with this function, even if it was not operating during the tests. As a matter of fact, such a system would have provided a greater cooling by the air-to-air heat exchanger $(23 \mathrm{~kW}$ instead of $13 \mathrm{~kW})$, with the effect of reducing the sensible requirements of the chiller. The PER of the system would have been 0.72 .

At the end of the 1990s, the chemical dehumidification plant designed with the contribution of Professor Lazzarin and his research team and realized at DTG was an absolute novelty for the air conditioning in Italy. The analysis of this pilot plant was useful to test the real behaviour of the technology. As described above, lower performance than predicted was revealed by monitoring the plant due to some problems in the control and circuit. The lack of experience of the installer and the control designer was probably the main cause. However, monitoring confirmed that significant energy savings could be obtained in annual climatization, particularly if the design were optimized to take full advantage of chemical dehumidification.

\subsection{Experimental and theoretical energy analysis of a heat pump desiccant dehumidifier}

In the following years, the group of Professor Lazzarin continued the research on chemical dehumidification by liquid absorption. In the first half of the first decade of $2000 \mathrm{~s}$, a selfregenerating liquid desiccant cooling system set up by an integrated electric heat pump for air dehumidification, cooling, and heating was on the market [37] (Figure 8).

The outside air to be treated flowed through a honeycomb cellulose medium, where it was dehumidified by the $\mathrm{LiCl}-\mathrm{H}_{2} \mathrm{O}$ solution. The latter was suitably precooled by the evaporator of the heat pump. In this process, the solution became diluted, and the air could escape cooler and dryer. The thermal energy for the regeneration of the desiccant solution was supplied by a primary heat pump condenser to the solution and by a secondary condenser to the regeneration air (left side of Figure 8). A fluid equalizer, whose operation mode was not described by the manufacturer, allowed the diluted solution to go to the regenerator, and the concentrated solution to return to the absorber. 

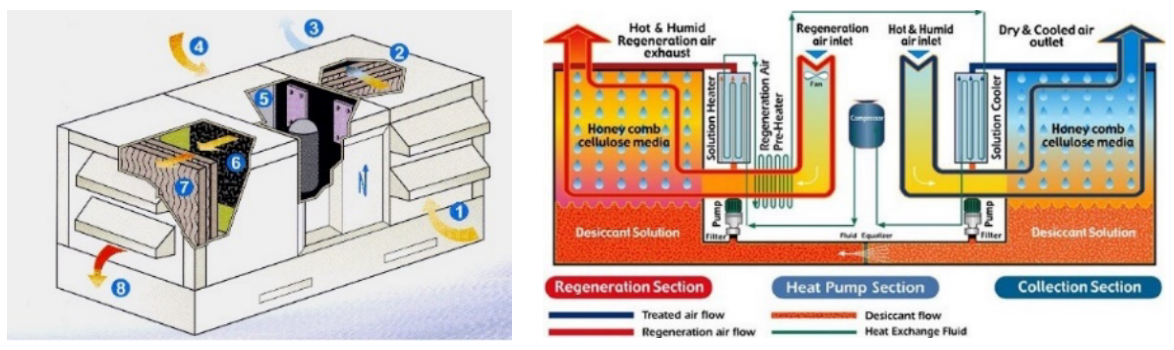

Fig. 8. The desiccant heat pump [37]. (1) Inlet of outside or recirculated air flow; (2) filtration, dehumidification, and cooling section; (3) cool and dry processed air flow outlet; (4) external air flow inlet; (5) heat pump; (6) condenser (heating section); (7) regeneration section; (8) outlet of hot and wet regeneration air flow.

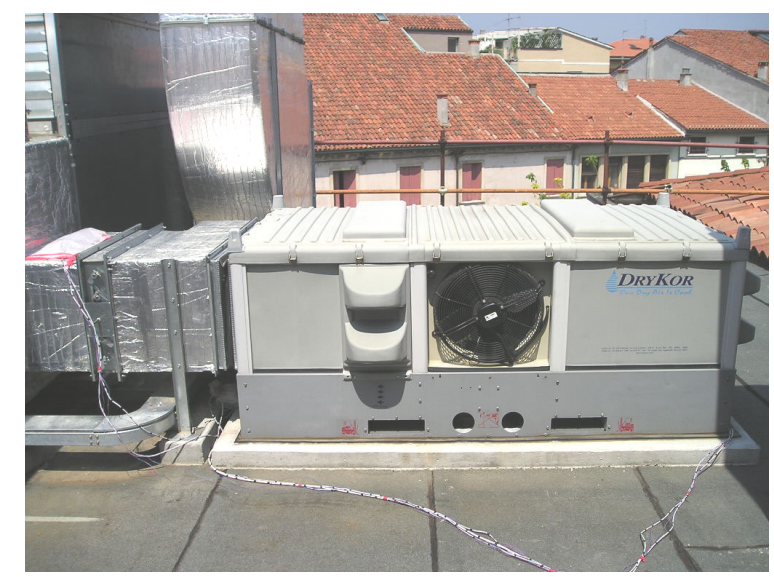

Fig. 9. The monitored unit.

The first study of this new equipment by the DTG group was carried out by monitoring a set of three units placed on the roof of a new building of the Vicenza Hospital in 2004 [38]. As the only unit available to install the monitoring equipment was number 3 (Figure 9), on the authors' request the control parameters were modified and the set point for internal humidity was set at $35 \%$ to let the unit work continuously for long time segments.

The measurement system was made of a data logger, which surveyed the temperature and humidity of outdoor air, process air and regeneration air. Electric power consumption of the machine itself, excluding the electric power to drive the main air handling unit fan, was also recorded. The volume flow of process air was measured at the beginning of the session by means of an auxiliary duct temporarily applied to the inlet grid, resulting in $0.884 \mathrm{~m}^{3} / \mathrm{s}$.

The experimental activity allowed to highlight that the performance of this device was quite far from what was expected by the manufacturer's catalogue and software, both in terms of humidity removal and COP: at the outside air temperature $30{ }^{\circ} \mathrm{C}$ and relative humidity $70 \%$, the smallest model featured a water removal rate of $31 / \mathrm{h}$ and a cooling of 7 ${ }^{\circ} \mathrm{C}$ of the $250 \mathrm{~m}^{3} / \mathrm{h}$ processed air (COP 3.2 ), while the greatest capacity model featured a 
water removal rate of $42 \mathrm{1} / \mathrm{h}$ and a cooling of $6{ }^{\circ} \mathrm{C}$ of the $4760 \mathrm{~m}^{3} / \mathrm{h}$ processed air (COP 4.2).

Moreover, the work identified some problems in the unit operations. As an example, Figure 10 reports the monitoring of data logging every second for a period of about 30 minutes on 12 September 2004: on the dehumidification side, the inlet and outlet air temperatures were kept more or less constant, whereas on the regeneration side, the air temperature showed sudden increases and decreases. Taking into account the electric power curve, sudden changes were found: a first main increase of about $3.2 \mathrm{~kW}$ and a second one of about $700 \mathrm{~W}$, which were identified, respectively, in the compressor start-up and the regeneration fan start-up. Taking advantage of the vertical line drawn between 12.14.24 $\mathrm{AM}$ and 12.15.07 AM, it can be appreciated that the changes in the temperature of the exhaust air flow from the regenerator occurred contemporaneously with activation of the regenerator fan. This kind of 'pulsating' operation on the regeneration side implied that the absorbed vapour was not balanced by the discharged vapour. As no closed-loop control on the concentration level was present, a decrease in the dehumidification capacity was expected in case of high humidity ratios of process air entering the dehumidification section for a long time.

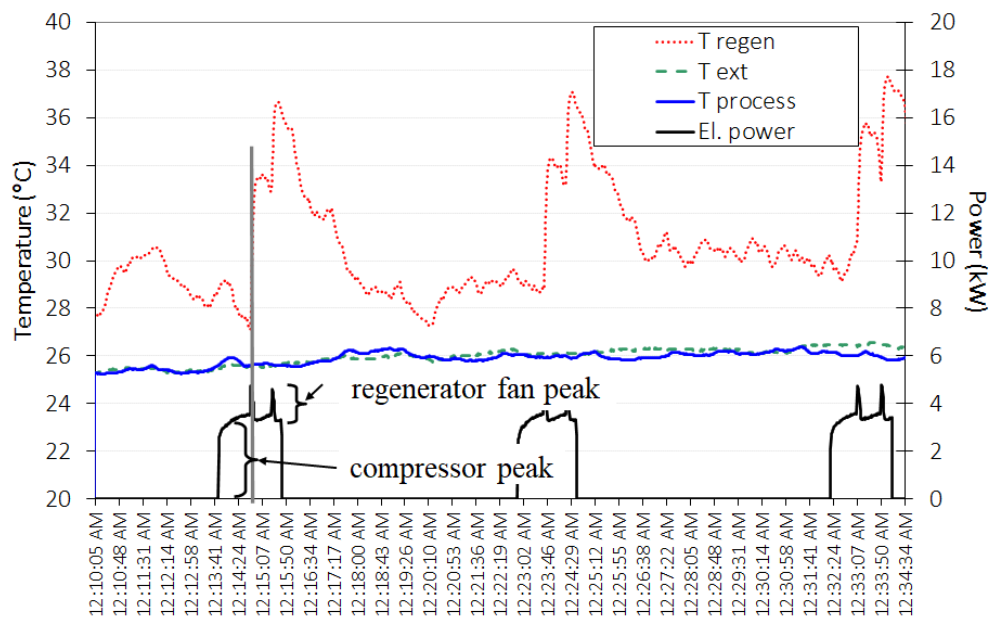

Fig. 10. Temperature and electric power, monitored every second, 12 September 2004.

The humidity removal rate, sensible cooling capacity and external temperature recorded every second were reported in Figure 11. The former was always positive, whereas sensible cooling was sometimes negative. As a matter of fact, the cooling capacity provided by the heat pump was inadequate not only for giving the air a suitable sensible cooling but even to get clear of the absorption heat of vapour into the solution.

Further analysis revealed that the COP lowered notably during the monitoring period, with a contemporary slight decrease in enthalpy removal and a remarkable increase in electric energy consumption. This was probably due to an overflow of the solution. The average COP during the summer operations, from 27th July to 9th September 2004, was around 2 . 


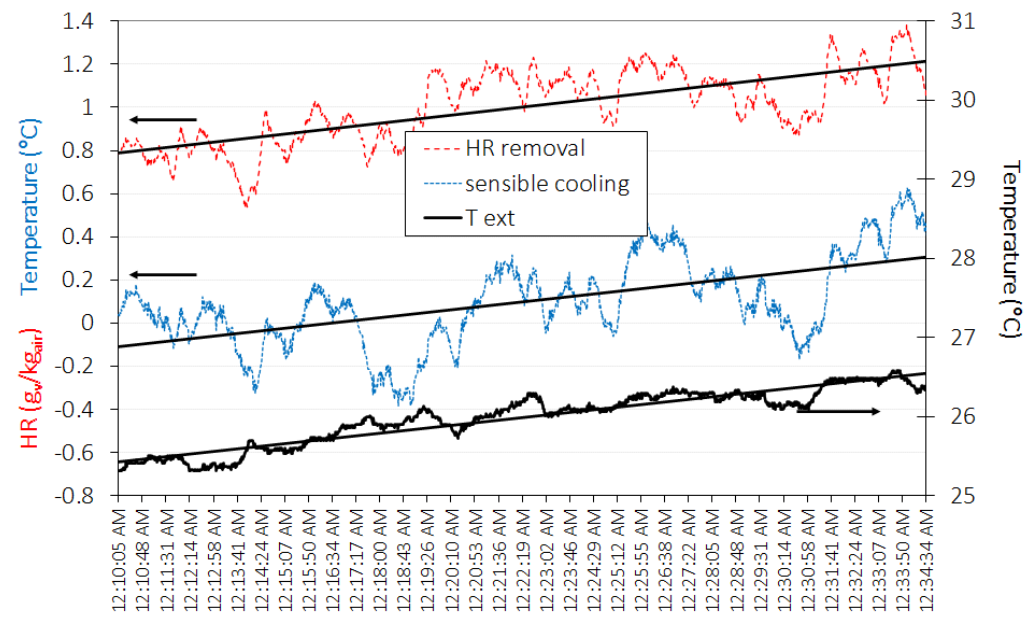

Fig. 11. External temperature, sensible cooling, and humidity removal rate of the process air, data collected on 12 September 2004.

Despite some operational problems highlighted by the experimental study, the authors performed a further analysis of the system [39]. A Trnsys ${ }^{\circledR}$ simulation model of a typical Italian supermarket (conditioned area of $2600 \mathrm{~m}^{2}$ and volume of $10,000 \mathrm{~m}^{3}$ ) was used to compare the energy performance of the innovative desiccant dehumidifier with a traditional air conditioning system (cooling and dehumidification below the dew point followed by the post-heating process). A primary energy savings in the range of $26 \%$ to $63 \%$ (based on the configuration of the condenser of the cabinets) could be obtained for the air conditioning on the average day of July (Figure 12). Such results allowed $5 \%$ to $22 \%$ energy savings in the global primary energy requirement of the supermarket.

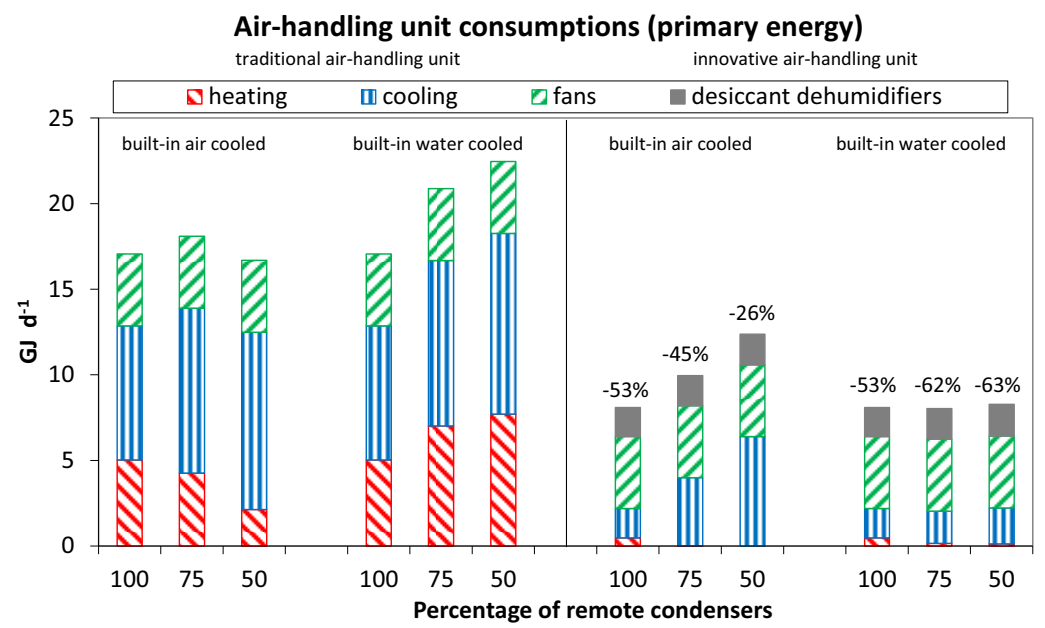

Fig. 12. Daily primary energy consumption (July) for innovative and traditional AHU varying the percentage of remote condensers and the cooling mode of the condensers. 
One of the main conclusions of the study was that no variation in supermarket global energy consumption occurred with innovative AHU, while traditional AHU energy consumption decreased with increasing relative humidity (to the optimum value of $60 \%$ ). Furthermore, the innovative equipment allowed higher energy savings when considering high density of cabinets with remote condenser or more humid climates (Figure 12). As a matter of fact, no substantial energy savings could be predicted in the modelled supermarket; instead, the optimum set point of air relative humidity decreased from $62 \%$ to $50 \%$ (Figure 13). This is a positive feature both for preventing frost formation in the cabinets and for indoor thermal comfort.

Annual supermarket primary energy consumption

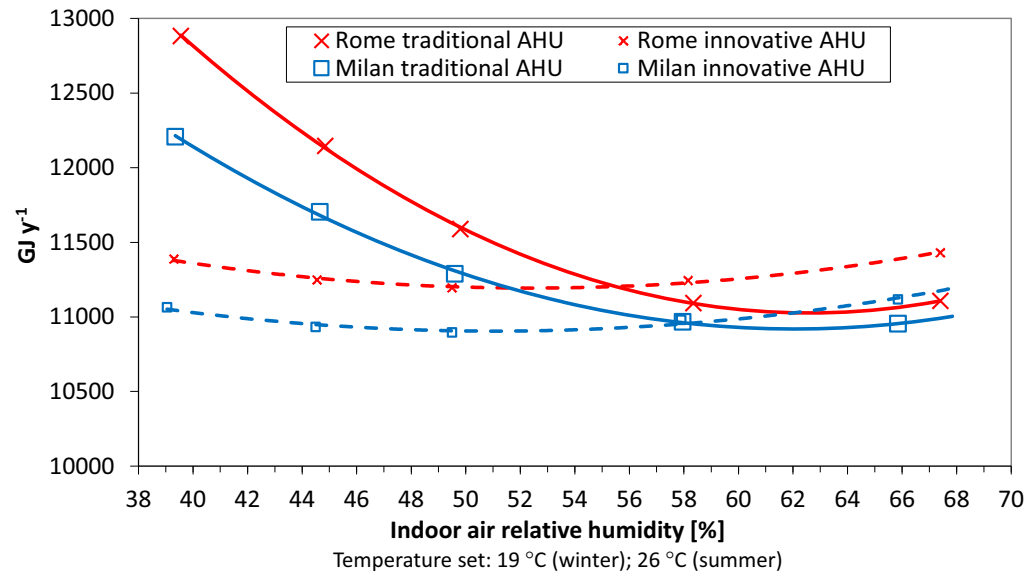

Fig. 13. Annual primary energy consumption of the supermarket for innovative and traditional AHU (constant air temperature, $19{ }^{\circ} \mathrm{C}$ in winter, $26^{\circ} \mathrm{C}$ in summer).

\subsection{Gas engine heat pump plant: energy and economic analysis for San Nicola DTG building}

The San Nicola building has been the site of the DTG since 1999. The renovation preserved the historical aspects of the building. Some characteristic data are: floor area $4200 \mathrm{~m}^{2}$, volume 14,300 $\mathrm{m}^{3}$, HVAC plant set up with fan coils for heating and cooling, and 21,700 $\mathrm{m}^{3} / \mathrm{h}$ AHU with cross-flow heat exchanger for ventilation (Figure 14).

The main characteristics of the GEHP and of the whole HVAC plant are reported in [19] [40]. Heating and cooling production was obtained until 2010 by means of a GEHP and two condensing boilers. During the first period of operation, the plant revealed some malfunctions. The monitoring analysis carried out by the authors allowed to highlight some mistakes in the commissioning phase; moreover, some lack of correct operation and maintenance of the system occurred. Those problems were due to different aspects: the first one was related to the high noise level of the heat pump disturbing the neighbourhood, which imposed some forced shutdowns. Consequently, the two boilers were used for heating. Additionally, an incorrect set point of the hot water produced was revealed ( 75 ${ }^{\circ} \mathrm{C}$ ), so no condensation of humidity on the exhaust could occur. As a matter of fact, the monitoring analysis carried out by the authors revealed an on-off instead of part-load operation of the heat pump due to some errors in the control strategy. As a consequence, the COP was low, a reduced thermal energy recovery was possible, and some thermo- 
mechanical stresses on the engine were induced. The authors proposed some technical solutions to improve the energy performance and control of the plant: soundproofing of the engine room, the correct reset of the set points, and a year-round contract for scheduled maintenance.

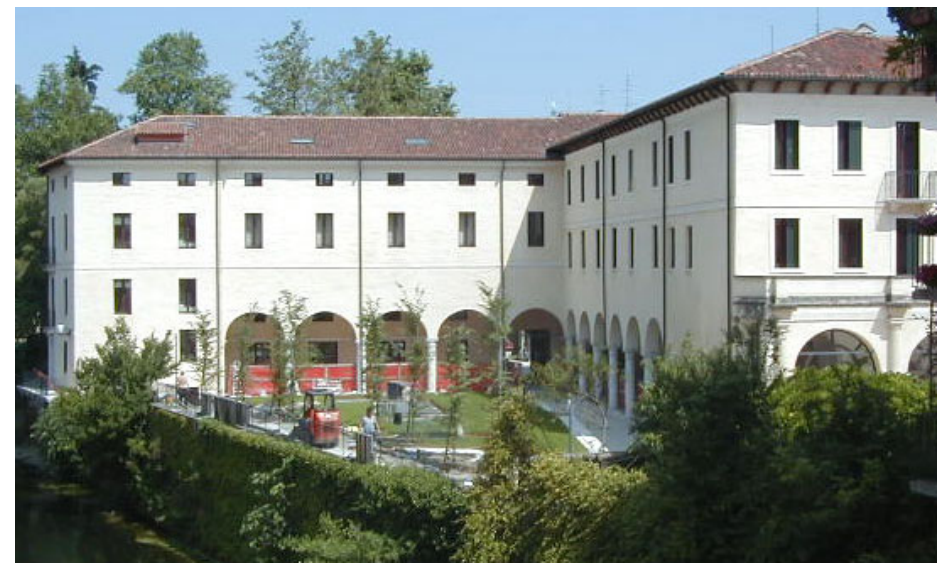

Fig. 14. San Nicola building, site of DTG.

Due to the drawbacks just described, during 2003 the University of Padova was evaluating the technical and economic offer of connection to the local district heating (DH) network. The authors performed an economical comparison of the actual plant versus the DH option, based on the investment cost of an electric air-water chiller and the operative costs of natural gas, electricity, and thermal energy, also taking into account the maintenance cost [19]. As a main result, the analysis highlighted that the DH option would have increased the total yearly cost from $60 \%$ to $80 \%$, so it would not ever have been a cost-effective solution.

During the following years of operation (2006-2009), the GEHP had some down periods due to failures, and thus extraordinary maintenance. As the GEHP was close to the half-life of the engine with a cost around 10,000 $€$, the dismantling of the equipment was considered by the service maintenance office. A new electric air-cooled chiller would have been provided for summer cooling, with the continuous use of condensing boilers for winter heating. Again, the authors developed an energy and economic comparison between the alternative proposed and the existing plant [40]. Suitable hypotheses on the cost and consumption of natural gas (in terms of $\mathrm{Nm}^{3}$ per 'degree hour'), determined by some test days monitoring natural gas consumption and outdoor temperature were considered. The investment cost was fixed at 40,000 $€$, and the increase in available electric power for the chiller to be bought in the alternative 'only condensing boilers' was evaluated from $100 \mathrm{~kW}$ to $230 \mathrm{~kW}$. Some more hypotheses on the determination of the natural gas and electricity consumption of the two alternatives based on building energy needs simulated by Trnsys ${ }^{\circledR}$ allowed to evaluate the yearly cost of climatization in both cases ("boiler + chiller" and "actual system"). 


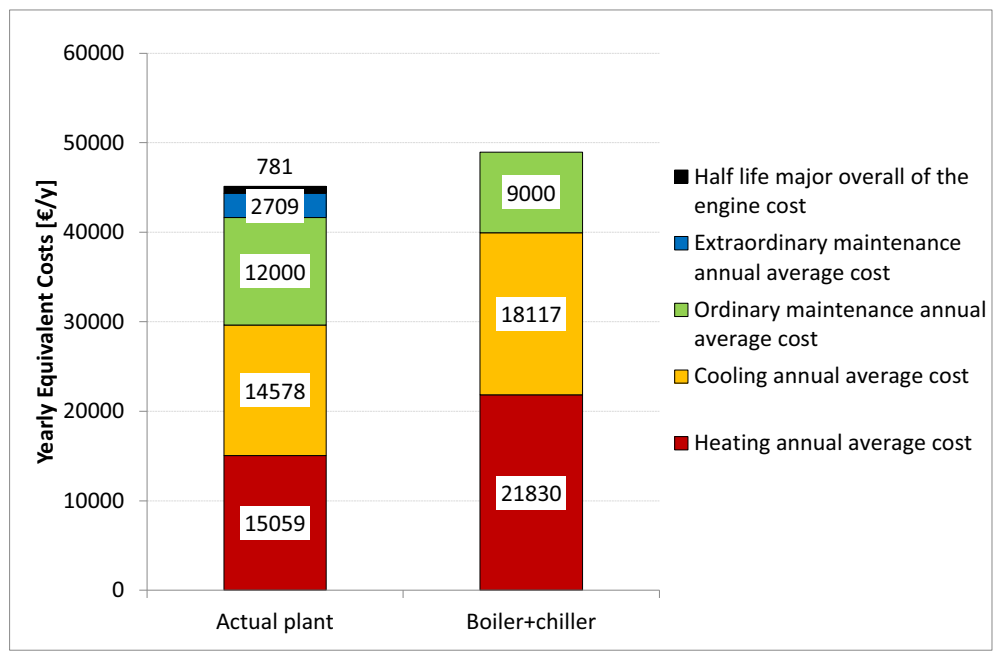

Fig. 15. Components of annual costs for the two alternatives (analysis period 11 years, interest rate $3 \%)$.

Figure 15 reports the outcome, taking into account the yearly extraordinary and ordinary maintenance costs (with a period of the analysis of 11 years and an interest rate of $3 \%$ ). The half-life major overall engine cost was also considered. Maintaining the actual plant allowed for an annual economic savings of $3800 €$. The yearly equivalent saving (YES) was higher than 20\%: keeping the actual plant revealed to be definitely more advantageous than moving to the 'boiler + chiller' solution (Figure 16).

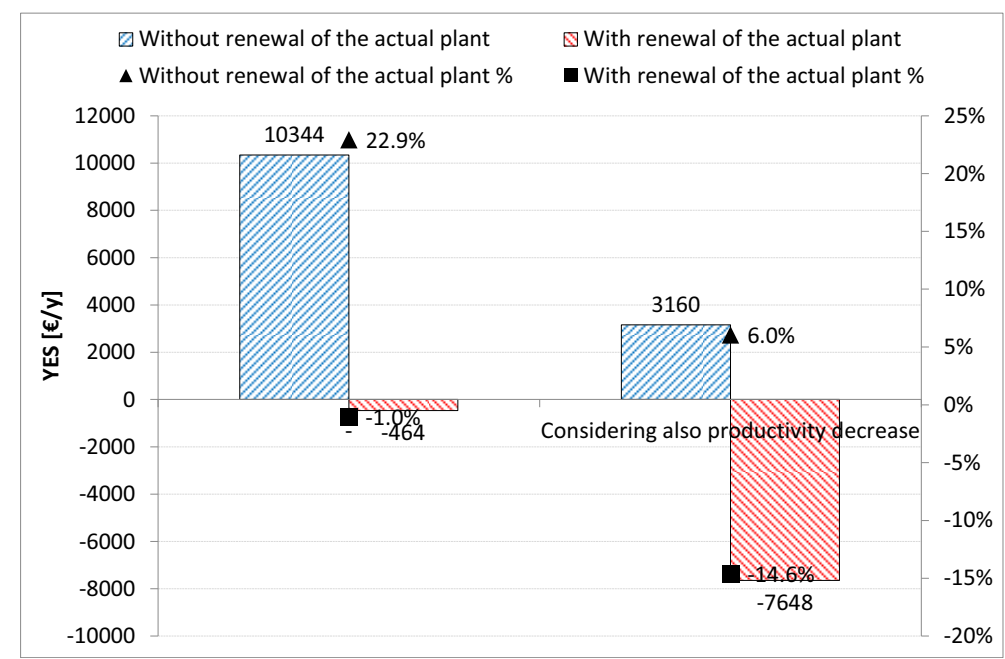

Fig. 16. Yearly Equivalent Savings of the 'actual plant' vs 'boiler + chiller' solution. The analysis was developed considering and not considering the renewal of the actual plant, and the productivity decrease due to the down periods during summertime. 
Table 1. Contemporaneity factors for workers at DTG and cost estimation for the productivity decrease.

\begin{tabular}{cccc}
\hline & June & July & September \\
\hline $\begin{array}{c}\text { Contemporaneity Factors of Professors and Researchers } \\
\text { Contemporaneity factor of administration staff }\end{array}$ & 0.50 & 0.30 & 0.30 \\
Average hourly cost of work $[€ / \mathrm{h}]$ & 0.95 & 0.90 & 0.90 \\
{$\left[\epsilon_{\text {lost }} / \mathrm{h}\right]$} & 1638 & 1140 & 1140 \\
$26-28\left[{ }^{\circ} \mathrm{C}\right]$ & & & \\
$28-30\left[{ }^{\circ} \mathrm{C}\right]$ & 86 & 60 & 60 \\
$>30\left[{ }^{\circ} \mathrm{C}\right]$ & 139 & 97 & 97 \\
Down time $[\mathrm{h}]$ & 164 & 114 & 114 \\
{$\left[\epsilon_{\text {lost }}\right]$} & 52.0 & 52.0 & 32.5 \\
$26-28\left[{ }^{\circ} \mathrm{C}\right]$ & & & \\
$28-30\left[{ }^{\circ} \mathrm{C}\right]$ & 1408 & 1027 & 447 \\
$>30\left[{ }^{\circ} \mathrm{C}\right]$ & 1122 & 1587 & 252 \\
Total $[€]$ & 511 & 830 & 0 \\
& 3769 & 3757 & 1130 \\
\hline
\end{tabular}

As a final step, the analysis also included the productivity decrease due to the down periods of the GEHP during summertime. By means of a 'penalty factor', measuring the productivity decrease for a higher indoor air temperature with respect to the reference temperature of $22{ }^{\circ} \mathrm{C}$, and evaluating the contemporaneity factor for each category (professors, researchers, administration, and employee staff) and per month, the cost of penalization was calculated (indicated as $\left[€_{\text {lost }} / \mathrm{h}\right]$ in Table 1). Thus, considering the number of hours of down, the cost of decrease of productivity was determined, which was not negligible (Figure 16): the YES was quite neutral in case a complete renewal of the actual system was not considered, while it was definitely negative if the renewal was considered.

Finally, the energy and economic balances based on total costs for the whole period 1999-2009 are reported in Table 2. The actual solution allowed for both economics and primary energy, with 0.45 electrical efficiency, savings that made it definitely more advantageous than the 'boiler + chiller' one. Actually, the authors proved that the correct choice was not to dismantle the existing plant. A more accurate skill in the maintenance and supervision of the plant by the maintenance firm could have avoided the indoor discomfort conditions featured during some periods.

Table 2. Energy and economic balances in the period 1999-2009.

\begin{tabular}{cccc}
\hline & & Actual plant & Boilers+chiller \\
\hline Average heating gas consumption & {$\left[\mathrm{Nm}^{3}\right]$} & 21,763 & 31,547 \\
Average cooling gas or electricity consumption & {$\left[\mathrm{Nm}^{3}\right][\mathrm{kWh}]$} & 20,928 & 78,965 \\
Heating annual average cost & {$[€ / \mathrm{y}]$} & 15,059 & 21,830 \\
Cooling annual average cost & {$[€ / \mathrm{y}]$} & 14,578 & 18,117 \\
Ordinary maintenance annual average cost & {$[€ / \mathrm{y}]$} & 12,000 & 9000 \\
Extraordinary maintenance annual average cost & {$[€ / \mathrm{y}]$} & 2709 & 0.00 \\
Half-life major overall of the engine cost & {$[€ / \mathrm{y}]$} & 781 & 0.00 \\
Total annual average cost & {$[€ / \mathrm{y}]$} & 45,127 & 48,947 \\
Primary energy balance 1999-2009 & {$[\mathrm{kWh}]$} & 409,824 & 478,334 \\
Economic balance 1999-2009 & {$[€]$} & 496,393 & 538,422 \\
Primary energy savings 1999-2009 & {$[\mathrm{kWh}]$} & 68,510 & \\
Cost savings 1999-2009 & {$[€]$} & 42,029 & \\
\hline
\end{tabular}




\subsection{Design and operation of a multisource heat pump plant: the importance of monitoring}

Since 2006, the authors have contributed to the design, monitoring and data analysis of the multisource absorption heat pump plant installed in a new school building in Agordo (North Italy). On this site, the climate is temperate (Köppen climate classification: $\mathrm{Cfb}-\mathrm{Cfc}$ ); cold winters (3376 heating degree days) and mild or cool summers are reported. The main characteristics of the building are: $5680 \mathrm{~m}^{2}$ of heated area and 19,640 $\mathrm{m}^{3}$ of gross heated volume (Figure 17).

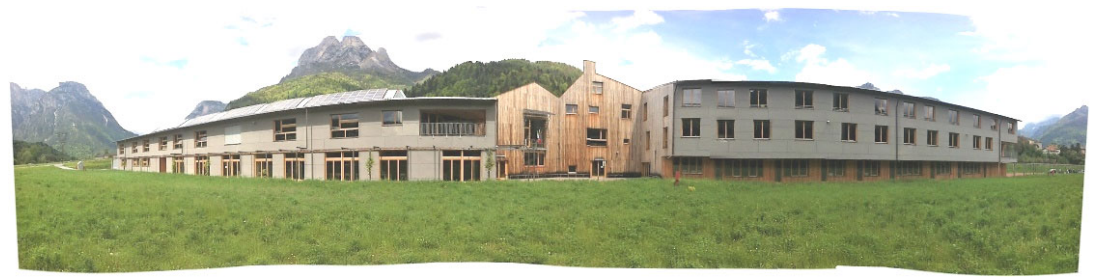

Fig. 17. The school building in Agordo (from south).

The plant was designed only for heating and ventilation, as no cooling was requested for the building during summer and the limited demand for hot tap water was satisfied by electric water heaters (Figure 18).

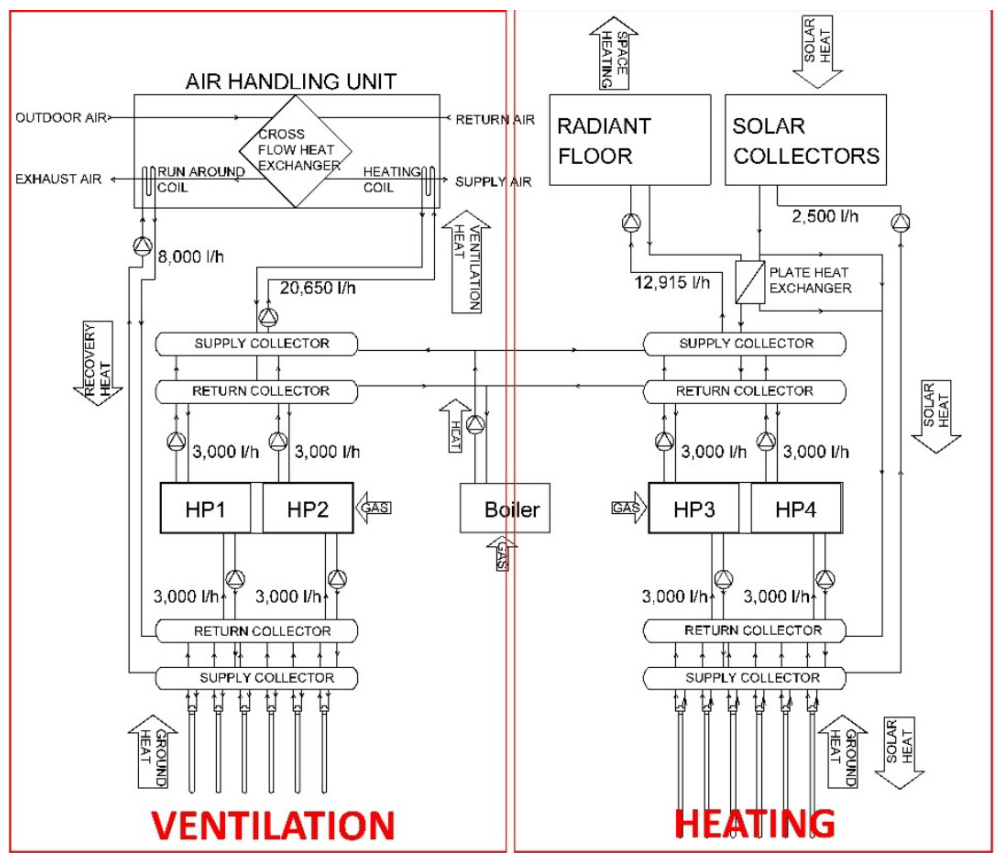

Fig. 18. HVAC plant (the main mass and energy flows such as gas, ground, solar, and recovery are shown). 
The space heating and ventilation sections of the HVAC plant featured two ammoniawater absorption heat pumps (Robur GAHP-W-LB model, HP1-HP4 in Figure 18). They produced thermal energy at $45^{\circ} \mathrm{C}$ and $55^{\circ} \mathrm{C}$, respectively. The ground exchanger $(6 \times 160$ $\mathrm{m}$ in parallel row for the heating section, $6 \times 125 \mathrm{~m}$ in row for the ventilation section) was a vertical double $U$ pipe (outer diameter $32 \mathrm{~mm}$, thickness $2.9 \mathrm{~mm}$ ). Solar thermal collectors (50 $\mathrm{m}^{2}$ of flat type) operated with different modes: when the measured solar radiation exceeded a minimum threshold, the solar system was activated. The plate heat exchanger was bypassed unless the temperature at the outlet of the solar circuit exceeded the supply temperature of the radiant floor increased by $3{ }^{\circ} \mathrm{C}$, i.e. $38^{\circ} \mathrm{C}$ : in this case, the solar outlet was directed to the plate heat exchanger (Figure 18). Successively, the solar outlet fed the HP3 and HP4 evaporator collector: this was useful to increase the evaporation temperature. Instead, a regeneration of the ground by the solar outlet was provided in case there was no need for space heating [41].

The AHUs of the ventilation section featured static cross heat recuperators (efficiency $50 \%$ ). At the outlet of two of the four AHUs (laboratory and teaching rooms, total flow rate $20,600 \mathrm{~m}^{3} \mathrm{~h}^{-1}$ ) run-around coils were operated in case the external temperature was higher than $0{ }^{\circ} \mathrm{C}$; the heat recovered was directed to the absorption heat pump evaporator following a suitable control logic. The condensing boiler acted as a backup of the heat pumps, and to cover the peak load (Table 3 ).

Table 3. Heating generators of the central HVAC plant.

\begin{tabular}{ccc}
\hline Component & Rated capacity (kW) & Rated efficiency \\
\hline HP1 + HP2 & 74 (B0W60) & 1.25 (GUE) \\
HP3 + HP4 & 76 (B0W40) & 1.40 (GUE) \\
Boiler & 114.4 & 1.02 (condensing) \\
\hline
\end{tabular}

After the design of the plant and the control logic, the authors contributed to the analysis of recorded data from May 2012 to April 2017 [42]. Cumulative energy flows were recorded hourly:

- Evaporator and condenser for each heat pump;

- Ground circuits (ventilation and space heating separately);

- Primary circuit of AHU heating coils and run-around coils;

- Solar circuit;

- Primary circuit of the radiant floor.

The natural gas consumptions of the heating/ventilation system were deduced from the bills.

The analysis of the data operation of the plant allowed to reveal long periods of shutdown of the solar section due to the non-substitution of one single collector; furthermore, the boiler had priority to the heat pumps. As the heating service continued to be assured and the natural gas demand was almost steady or in slight decrease, the management was unaware of the bad working of the plant. This was revealed only thanks to the careful analysis of available data records by the authors, which highlighted the missed potential energy savings (Table 4).

Contributions to ventilation and space heating demands are reported by the energy balance of the plant (Figure 19). The figure also reports the specific consumption of primary energy (PE) (i.e., NG requirement, expressed in $\mathrm{kWh}$ per square meter of heated area) and the total PER of the plant (that is, the ratio between the thermal energy produced by boiler, heat pumps, and free renewable energy (solar+static recuperator) for heating and ventilation, and the primary (not renewable) energy consumed). For the first two monitored seasons (12/13 and 13/14) the plant control was correct (i.e., with priority to heat pumps and boiler as backup), allowing a high value of the total PER. Instead, a considerable 
decrease was reported in the following two seasons (Table 4), as the heat pumps of the heating section and the solar field did not operate for long periods. The reset of the correct operation of that equipment in the following last season monitored (2016-2017) allowed the $\mathrm{PE}$ and PERtot to assume correct values.

Table 4. Priority of the generators of the heating section and solar field operation for the monitored period.

\begin{tabular}{cccc}
\hline & & Heating section & \\
\hline Heating season & Generator priority & Generator backup & Solar field \\
\hline $2012-2013$ & HP3+HP4 & Condensing boiler & $09 / 12-04 / 13$ OFF \\
$2013-2014$ & HP3+HP4 until 02/14, then & Condensing boiler till & Till 12/13 OFF \\
$2014-2015$ & condensing boiler & 02/14, then HPs & $08 / 14-04 / 15$ OFF \\
$2015-2016$ & Condensing boiler & HP3+HP4 & $05 / 15-04 / 16$ OFF \\
$2016-2017$ & Condensing boiler & HP3+HP4 & $05 / 16-09 / 16$ OFF \\
\hline
\end{tabular}

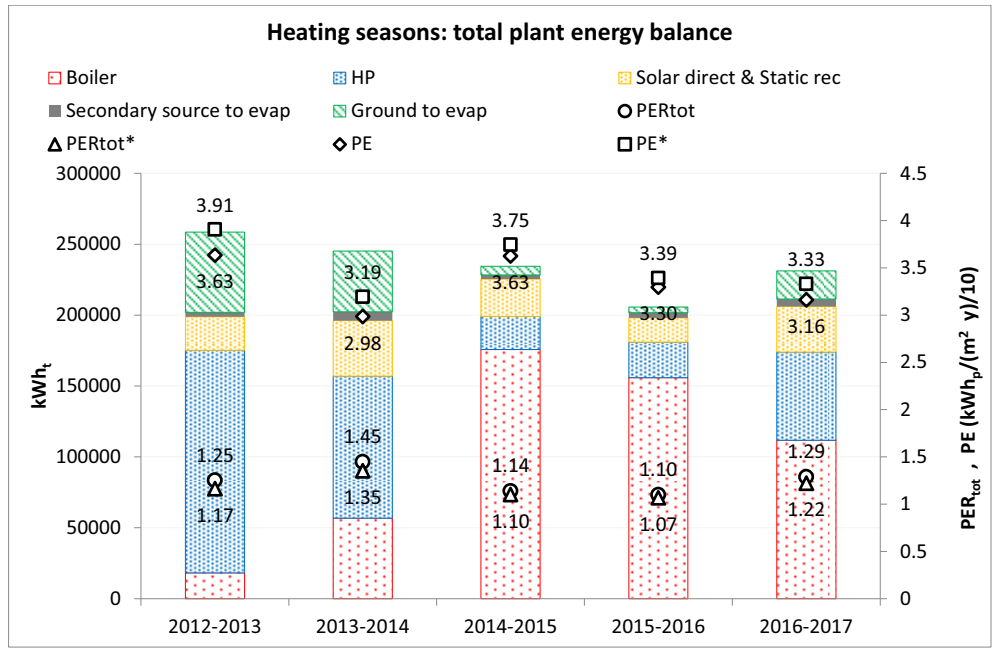

Fig. 19. Different contributions by heat pumps generators (HP), by heat pumps evaporators (ground and secondary sources), by static recuperator, by direct solar, by boiler, expressed as thermal energy) to the heating + ventilation energy requirement; total PER; specific PE consumption. PERtot* and PE* also considered the electricity consumption of pumps.

Figure 20 reports annual NG consumption, total thermal energy request, and annual HDD for further analysis. Comparing only the NG consumption can be misleading. In fact, very different HDD were monitored in the $12 / 13$ and $14 / 15$ seasons ( 3795 vs. 3361 ) even if very similar (high) values of NG consumption were detected; thermal energy demands varied as well. During the $13 / 14$ season, a 5\% decrease of thermal energy demand and an $18 \%$ decrease of NG consumption were detected compared to the previous season $(12 / 13)$, when the plant was operated correctly. This analysis confirmed that when the plant operated correctly, that is, with priority to the heat pumps, it featured efficient performance. Instead, the following heating season (14/15) featured a negative energy performance, as primary energy consumption increased $(+18 \%)$ even with a decrease of $4 \%$ of thermal energy demand. 
Comparing the 2015/2016 season with 2013/2014, a 9\% decrease in NG consumption was detected while a $16 \%$ increase in thermal energy requirement was calculated. Considering that HDD were $11 \%$ lower, it could be concluded that, in addition to HDD, other variables influenced the thermal requirement of building (i.e., a higher solar or internal heat gain and the HVAC plant shut-off during Christmas holiday).

As a matter of fact, in the 2015-2016 season a lower NG consumption $\left(14,900 \mathrm{Sm}^{3}\right.$ instead of $19,600 \mathrm{Sm}^{3}$ ) would have been recorded by managing the HVAC plant like in 2013-2014 (clearly with the same climatic conditions and set-point temperature during holiday periods). $5000 \mathrm{Sm}^{3}$ of savings can appear to be not so significant, but this is due to the very high thermal insulation of the building: notable higher energy and economic losses, even 5-6 times, would have been possible by such management of HVAC plant in case of poorer insulated buildings.

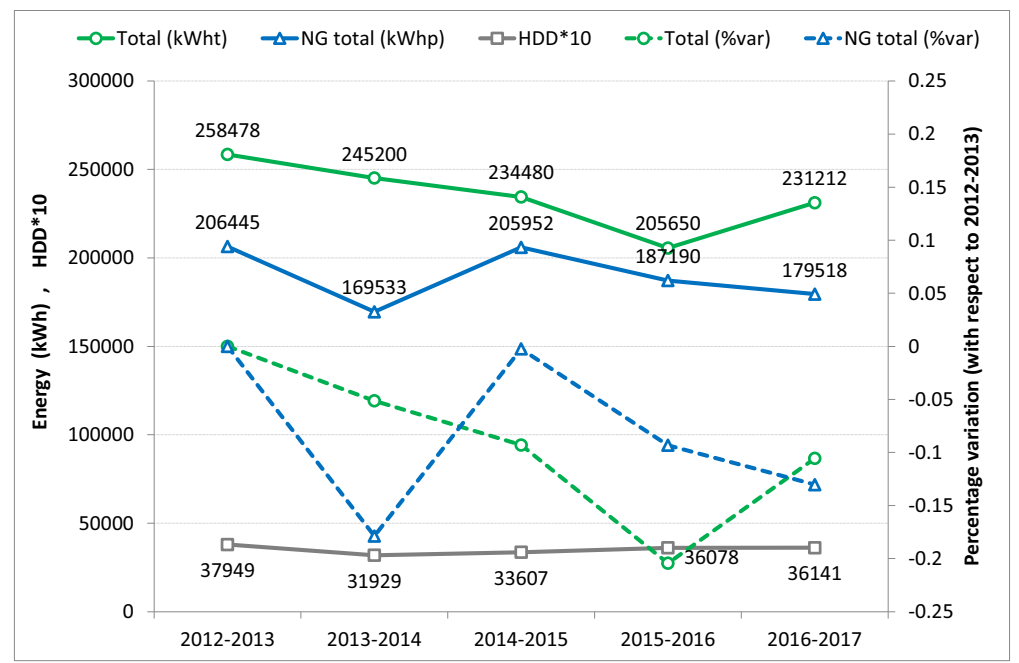

Fig. 20. $\mathrm{NG}$ consumption (in $\mathrm{kWh}_{\mathrm{p}}$ ), thermal energy demand (in $\mathrm{kWh}_{\mathrm{t}}$ ), and heating degree days (HDD) for the heating seasons considered.

Finally, Figure 20 reports that a more thorough operation of the plant allowed improved performance during the last heating season, with a $4 \%$ decrease in NG consumption in connection with a $10 \%$ increase in thermal need with respect to the previous $15 / 16$ season.

Some lessons have been learned by the authors after the in-depth energy analysis they conducted concerning the plant management service typical behaviour, especially in multisource heat pumps systems: the main purpose is to assure the heating (and cooling) service, regardless of the lower than target energy performance operation. For example, in the event of a component failure, it could be replaced not immediately if the plant does not stop. The heating load is often affected not only by the HDD, but also by other variables like solar radiation and set points (which can often be selected by the users). Finally, potential energy and economic saving can be lost by an Administration if it relies only on the bill costs: the latter can reduce during time, but less than possible.

The correct reset of the operation to the designed working conditions, due to the energy analysis by the authors, led to the recognition of a refund for $4816 \mathrm{Sm} 3$ of gas by the management company to the school owner (the Belluno Province Administration). 


\subsection{PCM vs. sensible thermal energy storage in solar cooling and heating plants: optimization analysis}

During the first phase of this research, annual dynamic simulations by Trnsys ${ }^{\circledR}$ were carried out on an existing building (office) located at the Casaccia Research Centre of the Italian National Agency for New Technologies, Energy and Sustainable Economic Development (ENEA) (near Rome, Italy). The building had a total floor surface of $230 \mathrm{~m}^{2}$ and a volume of $620 \mathrm{~m}^{3}$.

The solar heating and cooling plant presented two water thermal storages. The first one $(1500 \mathrm{~L})$ was coupled to the solar field, set up by a parallel of five arrays of three solar thermal collectors in series. It could drive the absorption chiller in the summer cooling season ('hot' storage) and face the heating loads during the winter season ('warm' storage). The second thermal storage $(1000 \mathrm{~L})$ operated in the cooling season as a 'cold' tank. A natural gas boiler operated as backup/integration (Table 5). During the heating season, the fan coils of the first and second floors were supplied by the boiler, while the radiant floors were supplied by the solar heat storage. Instead, the fan coils and the radiant floor could operate simultaneously during the cooling season [43].

Table 5. Main equipment of the solar cooling/heating plant.

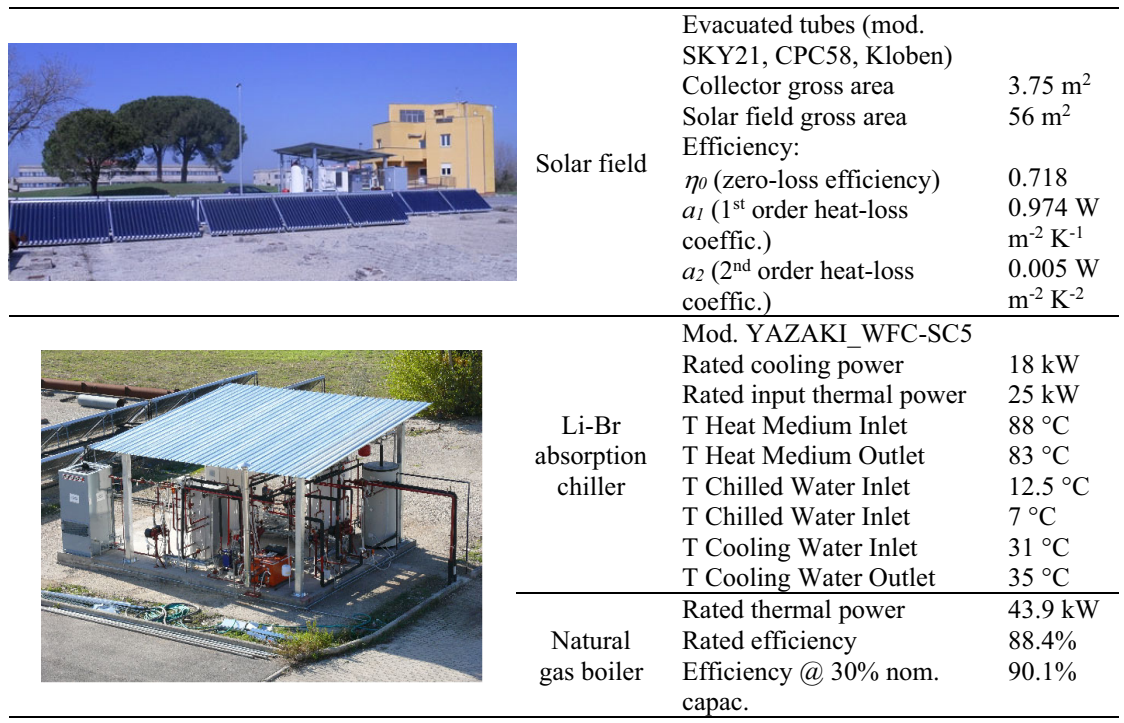

The main objectives of the study were a maximization of the economic advantage and minimization of the primary energy consumption referring to a traditional plant. This was done by the authors by optimizing the size of the tanks; furthermore, in order to use PCM instead of water in one of the two storages, an optimization of the solid-liquid phase-change temperature of the PCM was carried out.

Different scenarios were compared:

— both tanks were modelled in Trnsys ${ }^{\circledR}$ as sensible storage (water) (type 60);

— only the hot side tank was modelled as PCM storage (type 860, [44] [45]). In this case, both 'hot' (fusion around $89{ }^{\circ} \mathrm{C}$, named S89) and 'warm' PCM heat storage (fusion around $44^{\circ} \mathrm{C}$, named S44) were considered; 
— only the cold side tank modelled as PCM storage (fusion around $7^{\circ} \mathrm{C}$, named S7).

Type 860 was set with suitable values of the main parameters, that is, the temperatureenthalpy characteristic of the PCM, the characteristics of the HDPE plastic tube encapsulation, the specific heat capacity, the thermal conductivity, and latent heat of fusion heat (Table 6). The simulation model was calibrated using real data (Figure 21) during the first operation periods of the plant (9th February - 15th April 2012 for heating, 1st June 15th September 2012 for cooling).

Table 6. PCM thermophysical characteristics [43].

\begin{tabular}{|c|c|c|c|c|c|c|}
\hline $\begin{array}{l}\text { PCM } \\
\text { type }\end{array}$ & $\begin{array}{c}\text { Phase-Change } \\
\text { Temp. } \\
\left({ }^{\circ} \mathrm{C}\right)\end{array}$ & $\begin{array}{l}\text { Density } \\
\left(\mathrm{kg} \mathrm{m}^{-3}\right)\end{array}$ & $\begin{array}{c}\text { Latent Heat } \\
\text { Capacity } \\
\left(\mathrm{kJ} \mathrm{kg}^{-1}\right)\end{array}$ & $\begin{array}{l}\text { Volum. Heat } \\
\text { Capacity } \\
\left(\mathbf{M J ~ m}^{-3}\right)\end{array}$ & $\begin{array}{c}\text { Specific Heat } \\
\text { Capacity } \\
\left(\mathrm{kJ} \mathrm{kg}^{-1} \mathrm{~K}^{-1}\right)\end{array}$ & $\begin{array}{c}\text { Thermal } \\
\text { Conductivity } \\
\left(\mathbf{W} \mathbf{m}^{-1} \mathbf{K}^{-1}\right)\end{array}$ \\
\hline S89 & 89 & 1550 & 151 & 234 & 2.480 & 0.670 \\
\hline S44 & 44 & 1584 & 100 & 158 & 1.610 & 0.430 \\
\hline S7 & 7 & 1700 & 150 & 255 & 1.85 & 0.4 \\
\hline
\end{tabular}

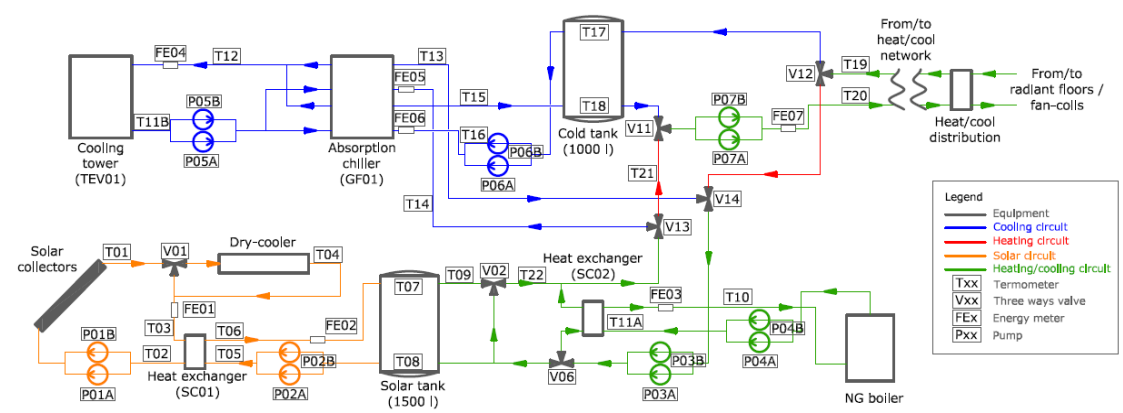

Fig. 21. Simplified scheme of the HVAC solar heating and cooling plant [43].

Figure 22 reports the comparison between sensible, hot, warm, and cold storages varying the capacity. The comparison was carried out in terms of no-renewable PE consumption (rated natural gas boiler efficiency of $90.1 \%$, primary energy factor for electricity of 0.46 ), primary energy savings (PES), and solar ratio. PES was calculated as the primary energy that should have been consumed by a 'traditional' plant based on a natural gas boiler to produce the same useful thermal energy produced by solar energy; solar ratio was defined as the percentage of the total thermal energy for heating and cooling needs covered by solar energy.

From an energy point of view, 3000-2000 L (PCM S44 'warm' tank - water sensible tank) was revealed to be the best solution (Figure 22). In fact, it featured a high PER, PES and solar ratio, and low global PE; furthermore, it featured low heat dissipated by the dry cooler coupled to the absorption chiller, and low NG consumption by the boiler (FE03). Figure 22 shows that a positive effect was detected by increasing the tank capacity. The PCM that performed better was S44 as the heating loads were higher than the cooling loads in the building considered. As a matter of fact, the phase-change temperature of this PCM was close to the storage mean operating temperature for longer during the year.

From an economic point of view, the solar plant was compared to a 'traditional' (set up by an NG boiler, absorption chiller, sensible water storage). The study revealed that 
sensible heat and cool storages allowed the best results (Figure 23). However, the use of a 'warm' tank (PCM S44) solution allowed for an economic advantage respect to the 'traditional' plant, given by solar plant and not by the PCM storage [43].

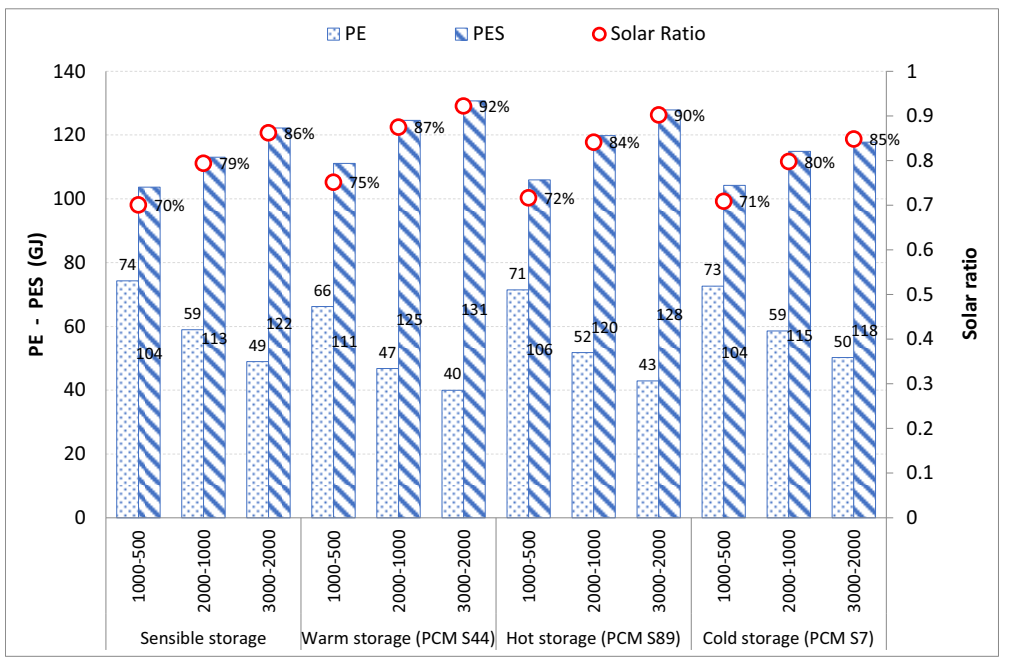

Fig. 22. Comparison of energy performance for three different tank capacity pairs (hot side tank-cold side tank, in litres).

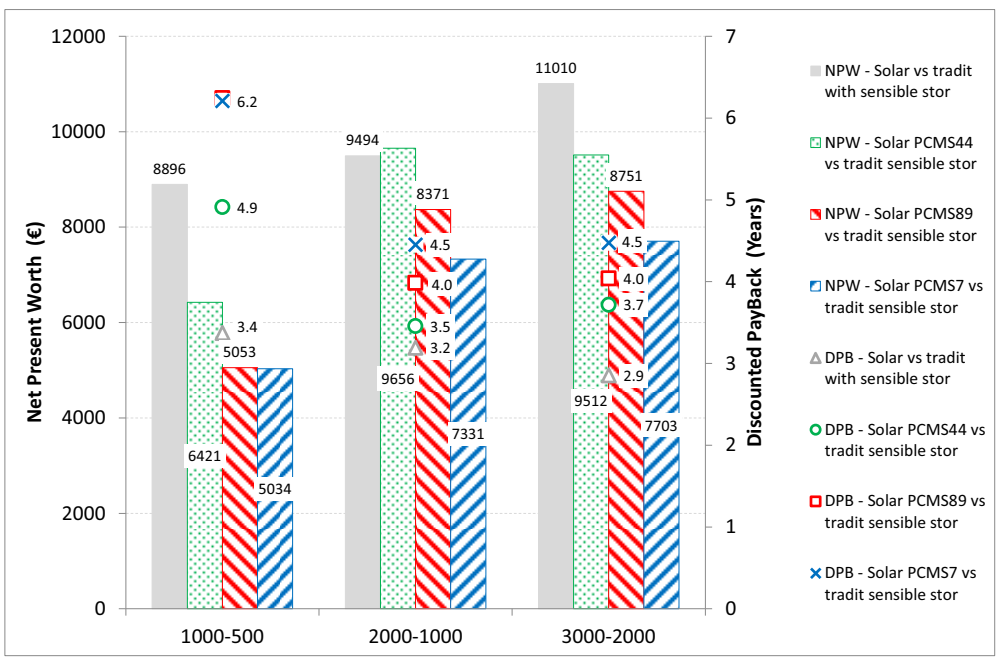

Fig. 23. Net Present Worth and Discounted PayBack period of the solar heating/cooling plant.

As a main conclusion of this study, the optimization of the size of system components from the energy point of view was possible only by a transient simulation. The best solution was the one for which the phase-change temperature of the PCM was near the mean 
operating temperature of the storage for longer during the year. This confirmed the main results of a previous study [46]. The economic analysis revealed that there was no advantage of PCM technology in a solar cooling plant due to the high investment cost, unless a lower PCM cost or a higher natural gas tariff would occur. During the following years, this research has been further developed by substituting the hot side tank of the plant by a S44 filled tank [47]. Experimental data substantially confirmed the energy advantage of the proposed solution.

As a more recent development of this topic, the authors developed some experimental and theoretical studies of hybrid water/PCM TES with enhanced PCM by means of aluminum foam, to increase the thermal conductivity of the PCM and to improve the energy performance of the TES [48-51].

\subsection{Solar cooling: electric vs. thermal comparison in different climates}

The analysis was performed by Trnsys ${ }^{\circledR}$ dynamic simulations on the same office building of Section 2.5, in two different Mediterranean climates (Trapani $38^{\circ} \mathrm{N}$ and Milan $45.5^{\circ} \mathrm{N}$, Italy). It considered only technologies available on the market:

- thermal collectors (PTC, ETC, and FPC) coupled to single and double effect $\mathrm{LiBr}$ absorption chillers (water tower cooled), or silica gel adsorption chiller (water tower cooled) or GAX ammonia-water chiller (air cooled);

- monocrystalline or amorphous photovoltaic modules, coupled to water or air cooled vapor compression chiller (Table 7, Table 8).

Table 7. Parameters of solar collectors (thermal at EN 12975 conditions, and photovoltaic at peak conditions).

\begin{tabular}{cccccc}
\hline Collector type & $\eta_{0}$ & $\begin{array}{c}\boldsymbol{a}_{1}(\mathbf{W} \\
\left.\mathbf{m}^{-2} \mathbf{K}^{-\mathbf{1}}\right)\end{array}$ & $\begin{array}{c}\boldsymbol{a}_{2}(\mathbf{W} \\
\left.\mathbf{m}^{-2} \mathbf{K}^{-2}\right)\end{array}$ & $\eta_{\text {PV,peak }}$ & $\begin{array}{c}\boldsymbol{A}_{\text {peak }}\left(\mathbf{m}^{\mathbf{2}}\right. \\
\left.\mathbf{k W}_{\mathbf{p}}^{-\mathbf{1}}\right)\end{array}$ \\
Flat Plate Collector (FPC) & 0.748 & 3.311 & 0.0087 & & \\
Evacuated Tube Collector (ETC) & 0.718 & 0.974 & 0.005 & & \\
Parabolic Trough Collector (PTC) & 0.6 & 0.36 & 0.0011 & & \\
PV mono-crystalline (PV mSi) & & & & $15.4 \%$ & 6.51 \\
PV amorphous (PV aSi) & & & & $7.2 \%$ & 13.83 \\
\hline
\end{tabular}

Table 8. Efficiency and capacity of the chillers (at A35W7; W30W7) at nominal conditions.

\begin{tabular}{|c|c|c|c|}
\hline Chiller type & & $\begin{array}{c}\text { Rated } E E R_{t h}- \\
E E R_{e}\end{array}$ & $\begin{array}{c}\text { Rated Capacity } \\
(\mathrm{kW})\end{array}$ \\
\hline Adsorption $\mathrm{H}_{2} \mathrm{O}$-Silica Gel (SilGel) & (Water cooled) & 0.45 & 15.0 \\
\hline Absorption $\mathrm{H}_{2} \mathrm{O}-\mathrm{LiBr}$ Single Effect ( $\left.\mathrm{LiBr} \_\mathrm{SE}\right)$ & (Water cooled) & 0.70 & 17.6 \\
\hline Absorption $\mathrm{H}_{2} \mathrm{O}-\mathrm{LiBr}$ Double Effect ( $\left.\mathrm{LiBr} \_\mathrm{DE}\right)$ & (Water cooled) & 1.10 & 23.0 \\
\hline $\mathrm{H}_{2} \mathrm{O}-\mathrm{NH}_{3}$ GAX $\left(\mathrm{NH}_{3} \_\mathrm{Air}\right)$ & (Air cooled) & 0.60 & 17.7 \\
\hline Electric vapor compression (VC_w) & (Water cooled) & 3.33 & 17.0 \\
\hline Electric vapor compression (VC_a) & (Air cooled) & 2.75 & 16.5 \\
\hline
\end{tabular}

The study focused on the systems listed on Table 9. Collectors' area, rated flow, and power consumption of the solar circuit pump were determined to have a solar ratio (as defined by Eq. (1) and Eq. (2)) of 70\%: 


\section{Solar ratio $=\frac{\text { Solar emergy to thermal emerge }}{\text { Caolng mee }} \quad$ (solar thermal cooling) $\quad$ Eq. 1 \\ Solar ratio $=\frac{\text { Chattlar electrichty from } P Y}{\text { Chitter electrichty total }} \quad$ (solar PV cooling) $\quad$ Eq. 2}

Table 9. The different solar cooling solutions considered.

\begin{tabular}{cc} 
System & Description \\
FPC_SilGel & Flat plate collector coupled to silica-gel adsorption chiller \\
FPC_LiBr_SE & Flat plate collector coupled to single-effect water-LiBr absorption chiller \\
ETC_LiBr_SE & Evacuated tube collector coupled to single-effect water-LiBr absorption chiller \\
ETC_LiBr_DE & Evacuated tube collector coupled to double effect water-LiBr absorption chiller \\
ETC_NH3_Air & Evacuated tube collector coupled to GAX ammonia-water absorption chiller \\
PTC_LiBr_SE & Parabolic trough collector coupled to single-effect water-LiBr absorption chiller \\
PTC_LiBr_DE & Parabolic trough collector coupled to double effect water-LiBr absorption chiller \\
PTC_NH3_Air & Parabolic trough collector coupled to GAX ammonia-water absorption chiller \\
PV mSi_VC_w & Monocrystalline silicon PV modules coupled to water-cooled vapor compress. chiller \\
PV mSi_VC_a & Monocrystalline silicon PV modules coupled to air-cooled vapor compression chiller \\
PV aSi_VC_w & Amorphous silicon PV modules coupled to water-cooled vapor compression chiller \\
PV aSi_VC_a & Amorphous silicon PV modules coupled to air-cooled vapor compression chiller \\
\hline
\end{tabular}

The whole energy performance comparison was done on the basis of the overall system efficiency (OSE), that is, the ratio by useful cooling effect and incident solar radiation. This was correlated with the chiller performance $\left(E E R_{t h}\right.$ or $\left.E E R_{e}\right)$ and the collector efficiency ( $\eta_{\text {th }}$ or $\left.\eta_{P V \text {,system }}\right)($ Eq. 3):

$$
\begin{gathered}
\text { OSE }=\frac{E_{\text {cool }}}{G_{\beta}}=\frac{E_{\text {cool }}}{E_{\text {coll }}} \cdot \frac{E_{c o l l}}{G_{\beta}}=E E R_{\text {th }} \cdot \eta_{\text {th }} \\
\text { OSE }=\frac{E_{\text {cool }}}{G_{\beta}}=\frac{E_{\text {cool }}}{E_{P V, \text { system }}} \cdot \frac{E_{P V, \text { system }}}{G_{\beta}}=E E R_{e} \cdot \eta_{P V, \text { system }}
\end{gathered}
$$

The $\mathrm{LiBr}$ double effect absorption chiller coupled with parabolic through collector featured the highest OSE in Milan (0.53); the second was the water-cooled chiller driven by monocrystalline PV (0.51) (Figure 24). The low-temperature adsorption system performed worse than the absorption system, as the higher efficiency of the collector coupled to the former did not balance the low $E E R_{t h}$.

The PV air-cooled solutions performed better than the air-cooled thermal system (OSE of 0.30 for PTC_NH3_Air, even 0.20 for ETC_NH3_Air). This was due both to the low efficiency of solar collectors (due to the high drive temperature of the GAX ammonia-water chiller), and to the low $E E R_{t h}$ of the chiller. The $O S E$ of both water and air cooled chillers driven by PV was dependent on the PV technology. Instead, the performance did not seem to be dependent on the climate on a seasonal basis.

The solutions were also compared on the base of the surface area needed to produce the cooling energy of $1 \mathrm{MJ}$ during a typical summer day (Figure 25). The thermal system PTC_LiBr_DE and monocrystalline PV coupled to a water-cooled chiller were the best for 
the Milan climate $\left(0.08 \mathrm{~m}^{2} \mathrm{MJ}^{-1}\right.$ per day). A reduced need of area was allowed by PV driven by water-cooled chillers with respect to air-cooled $\left(0.08-0.13 \mathrm{~m}^{2} \mathrm{MJ}^{-1}\right.$ per day, 0.11$0.17 \mathrm{~m}^{2} \mathrm{MJ}^{-1}$ per day, respectively, for mono-crystalline and amorphous silicon). For the climate of Trapani, thermal solar cooling solutions performed better, while the higher air temperature determined a lower $E E R_{e}$ of the chiller that was not balanced by the higher electricity produced (due to higher solar radiation).

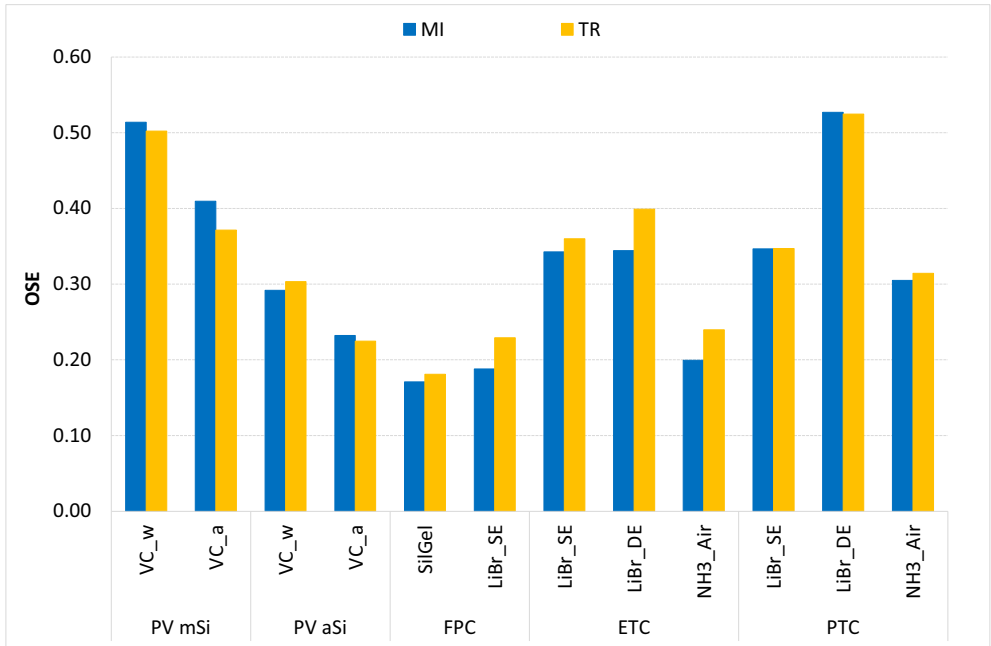

Fig. 24. Solar cooling solutions comparison on the basis of the overall system efficiency.

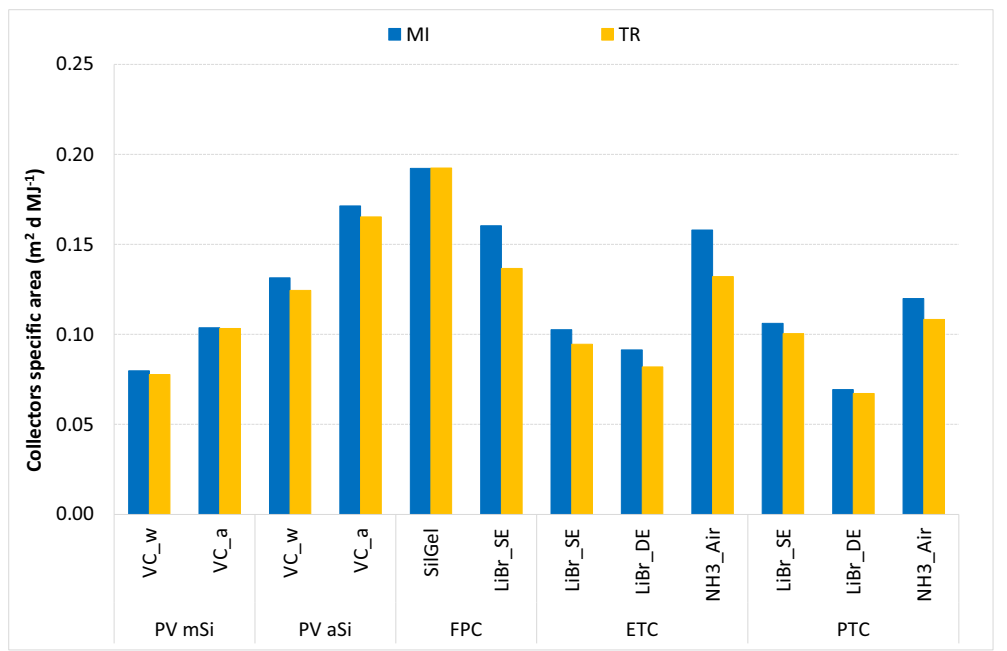

Fig. 25. Solar cooling solutions comparison on the basis of the specific collecting surface area (average day of July for Milan and of August for Trapani). 
The study also accounted for the electricity consumed by pumps and fans in solar thermal systems (about $10 \%$ in terms of primary energy).

The authors completed the study by an economic analysis taking into account the annual operating costs and the investment costs (solar collecting area + cooling equipment). With the hypothesis of continuous operation of the chiller for 10 hours a day, the lowest investment cost was calculated for water cooled PV aSi driven chillers $\left(25 € \mathrm{MJ}^{-1}\right.$ per day in Trapani) (Figure 26). The other electric chillers followed closely (30-43€ $\mathrm{MJ}^{-1}$ per day). Absorption chillers performed worse (PTC driven double effect: $53 € \mathrm{MJ}^{-1}$ per day; PTC driven single effect absorption chillers: $57 € \mathrm{MJ}^{-1}$ per day). Evacuated tube and flat plate collectors were definitely not attractive from the economic point of view. In climates with a less clear atmosphere (Milan), PV electrical options were not so much more expensive, whereas the solar thermal options were (from $10 \%$ to $40 \%$ increase of the investment cost). The advantage of PV-driven cooling technologies over thermally driven was definitely clearer for air-cooled chillers (respectively, $30 € \mathrm{MJ}^{-1}$ and $71 €$ per day).

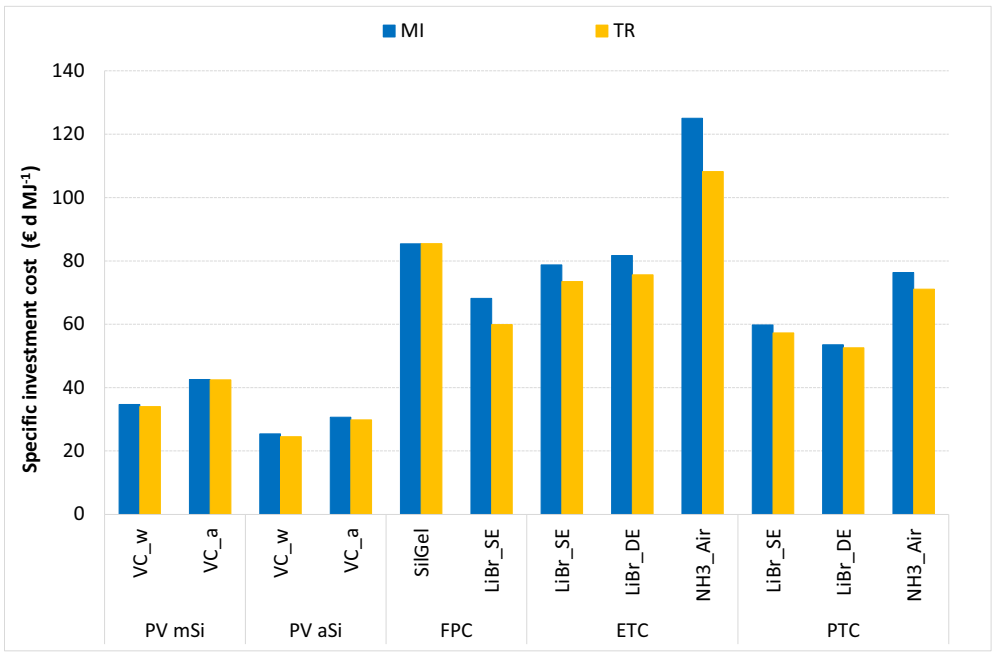

Fig. 26. Investment costs to produce the unit of cooling energy (typical summer day).

Table 10 reveals that the decrease in PV investment cost during the last years allowed the net present worth (NPW) of electric solar cooling solutions to be favourable compared to a traditional solution (air-cooled electric vapor compression chiller). The longest discounted payback period (DPB) was found to be 15 years; instead, it was 2.6 years only for amorphous silicon in Trapani. Solar thermal solutions were not advantageous: the higher operating costs (natural gas of the integration boiler and electricity of the auxiliaries) and the higher investment cost (solar part of the plant) were not balanced by the lower demand of electricity from the grid.

As the main conclusion of the study, the authors revealed the definitely better economic results of PV solar cooling solutions with respect to thermal solar cooling. This was due to the impressive cost reduction and increase of the electrical efficiency of photovoltaic energy during the last years. As a consequence, even without any economic support, PV solar cooling solutions are in direct competition with traditional solutions.

Table 10. Main results of the economic analysis. 


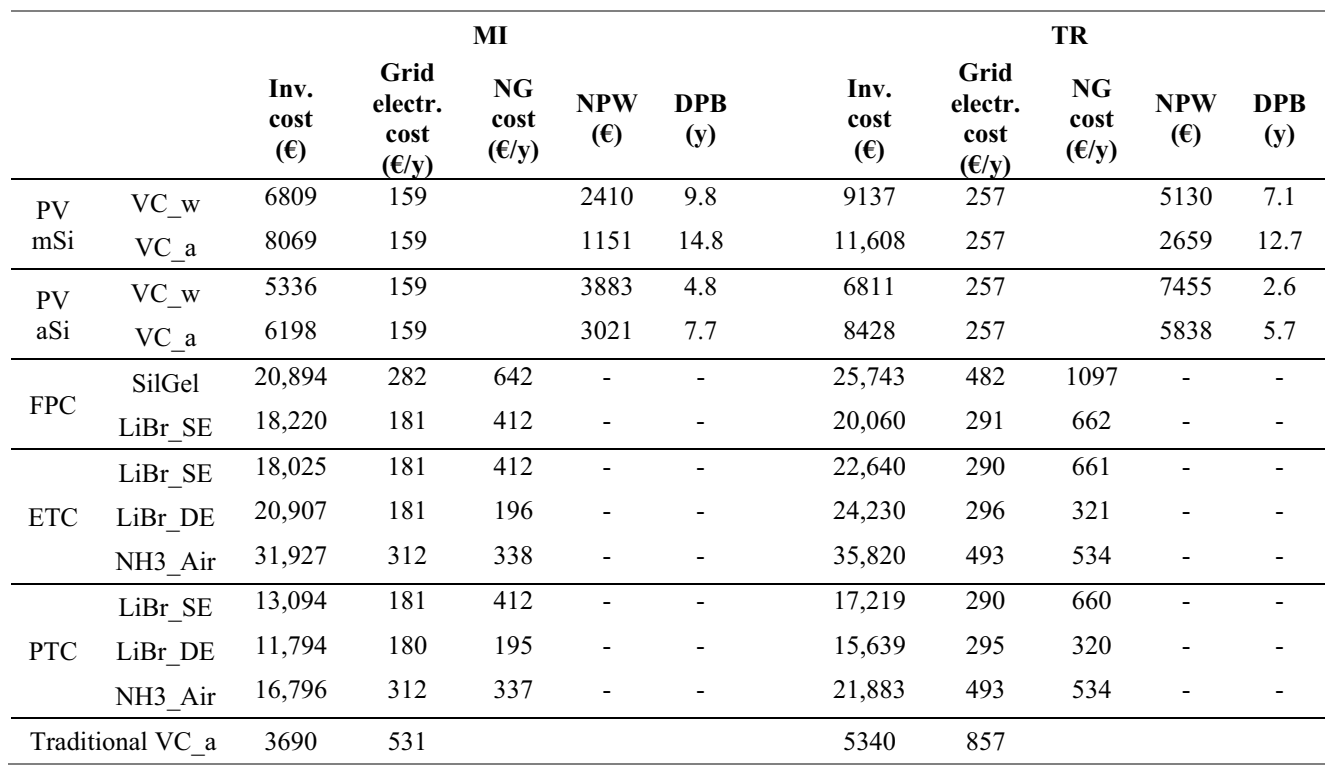

\section{Conclusions}

In this paper, some of the main relevant research studies on innovative HVAC plants and equipment carried out by Professor Lazzarin and his research group during the 2000-2015 period at DTG were described. All technologies and plant configurations developed by the authors revealed that a suitable design of the plant and its control logic are surely fundamental aspects. Furthermore, data monitoring during the real operation is a critical factor as well because it allows an in-depth energy analysis useful not only to prevent the energy performance to decrease over time, but to keep it at or even above the designed value.

\section{Abbreviations}

$\begin{array}{ll}\text { AHU } & \text { Air Handling Unit } \\ \text { COP } & \text { Coefficient Of Performance } \\ \text { DH } & \text { District Heating } \\ \text { DHW } & \text { Domestic Hot Water } \\ \text { EER } & \text { Energy Efficiency Ratio } \\ \text { ETC } & \text { Evacuated Tube Collector } \\ \text { FPC } & \text { Flat Plate Collector } \\ \text { GAX } & \text { Generator-Absorber Heat eXchange } \\ \text { HDD } & \text { Heating Degree Days } \\ \text { HVAC } & \text { Heating, Ventilation, Air Conditioning } \\ \text { LiBr } & \text { Lithium Bromide } \\ \text { LiCl } & \text { Lithium Chloride } \\ \text { NG } & \text { Natural Gas } \\ \text { OSE } & \text { Overall System Efficiency } \\ \text { PCM } & \text { Phase Change Material } \\ & \end{array}$




$\begin{array}{ll}\text { PE } & \text { Primary Energy } \\ \text { PER } & \text { Primary Energy Ratio } \\ \text { PES } & \text { Primary Energy Saving } \\ \text { PTC } & \text { Parabolic Trough Collector } \\ \text { PV } & \text { PhotoVoltaics } \\ \text { Sm }^{3} & \text { Standard cubic meter } \\ \text { TES } & \text { Thermal Energy Storage } \\ \text { YES } & \text { Yearly Equivalent Saving }\end{array}$

\section{References}

1. Y. Li, A. Mojiri, G. Rosengarten, C. Stanley, Energy and Buildings 250, 111234, (2021)

2. European Commission, Directive 2010/31/EU of the European Parliament and of the Council of 19 May 2010 on the energy performance of buildings (recast), Off. J. Eur. Union. (2010), pp. 13-35, 10.3000/17252555.L_2010.153.eng

3. European Commission, Directive (EU) 2018/2002 of the European Parliament and of the Council of 11 December 2018 amending Directive 2012/27/EU on energy efficiency, https://eur-lex.europa.eu/eli/dir/2018/2002/oj

4. European Commission, European Green Deal, 2019, https://ec.europa.eu/info/strategy/priorities-2019-2024/european-green-deal_en

5. R. Lazzarin, International Journal of Refrigeration 116, 146, (2020)

6. R. Lazzarin, Renewable energy technologies in air conditioning: State-of-the-art and perspectives. Refrigeration Science and Technology - Proceedings "25th IIR International Conference of Refrigeration, ICR 2019" 1846, 130, (2019)

7. R. Ukey, A.C. Rai, Energy and Buildings 244, 111050, (2021)

8. Z. Ma, H. Ren, W. Lin, Journal of Cleaner Production 240, 118158, (2019)

9. M. Bolzan, R. Lazzarin, Electric Power Research Institute (Report) EPRI NP 2, 827, (1980)

10. R. Lazzarin, M. Sovrano, Energie Alternative Habitat Territorio Energia 4(17), 221, (1982)

11. R. Lazzarin, M. Sovrano, Energie Alternative Habitat Territorio Energia 4(16), 113, (1982)

12. R. Lazzarin, G.A. Longo, F. Piccininni, Heat Recovery Systems and CHP 12(5), 391, (1992)

13. R. Lazzarin, G.A. Longo, A. Gasparella, International Journal of Refrigeration 19(3), 160, (1996)

14. R. Lazzarin, A. Gasparella, G.A. Longo, International Journal of Refrigeration 22(4), 334, (1999)

15. A. Giampieri, Z. Ma, A. Smallbone, A.P. Roskilly, Applied Energy 220, 455, (2018)

16. L. Bellia, A. Capozzoli, P. Mazzei, F. Minichiello, International Journal of Refrigeration 30(8), 1439, (2007)

17. P. Mazzei, F. Minichiello, D. Palma, Applied Thermal Engineering 25(5-6), 677, (2005)

18. R. Lazzarin, G.A. Longo, P.C. Romagnoni, Applied Thermal Engineering 16(7), 551, (1996)

19. R. Lazzarin, M. Noro, Applied Thermal Engineering 26(2-3), 193, (2006) 
20. R. Lazzarin, M. Noro, Applied Thermal Engineering 26(2-3), 244, (2006)

21. A. Hepbasli, Z. Erbay, F. Icier, N. Colak, E. Hancioglu, Renewable and Sustainable Energy Reviews 13(1), 85, (2009)

22. C. Roselli, E. Marrasso, M. Sasso, Energies 14(16), 4845, (2021)

23. G. Xu, X. Zhang, Taiyangneng Xuebao/Acta Energiae Solaris Sinica 27(11), 1148, (2006)

24. G. Zhou, Y. Liu, C. Zhang, C. Zhang, S. Chen, Proceedings of the 2010 5th IEEE Conference on Industrial Electronics and Applications, ICIEA 2010, 5515125, 878, (2010)

25. G. Emmi, C. Tisato, A. Zarrella, M. De Carli, International Journal of Energy Production and Management 1(4), 382, (2016)

26. G. Emmi, A. Zarrella, M. De Carli, Energy Conversion and Management 151, 386, (2017)

27. Y. Fan, X. Zhao, Z. Han, J. Li, A. Badiei, Y.G. Akhlaghi, Z. Liu, Energy 229, 120719, (2021)

28. L. Que, X. Zhang, J. Ji, L. Gao, W. Xie, L. Liu, X. Ding, Energy and Buildings 253, 111402, (2021)

29. M.F. Junaid, Z.U. Rehman, M. Čekon, J. Čurpek, R. Farooq, H. Cui, I. Khan, Energy and Buildings 252, 111443, (2021)

30. S. Mousavi, B. Rismanchi, S. Brey, L. Aye, Renewable and Sustainable Energy Reviews 151, 111601, (2021)

31. IEA, World Energy Outlook 2020, ISBN 978-92-64-44923-7, (2020)

32. P.R. Chauhan, S.C. Kaushik, S.K. Tyagi, Renewable and Sustainable Energy Reviews 154, 111808, (2022)

33. J. Settino, T. Sant, C. Micallef, M. Farrugia, C. Spiteri Staines, J. Licari, A. Micallef, Renewable and Sustainable Energy Reviews 90, 892, (2018)

34. M. Alobaid, B. Hughes, J.K. Calautit, D. O'Connor, A. Heyes, Renewable and Sustainable Energy Reviews 76, 728, (2017)

35. R. Lazzarin, A. D’Ascanio, Int. J. Energy Res. 31, 376, (2007)

36. G.A. Longo, A. Gasparella, Proceedings of 20th UIT National Heat Transfer Conference, 81, (2002)

37. DryKor Ltd., Beyond air conditioning-our dry air is cool, Illustrative Brochure, (2001)

38. R. Lazzarin, F. Busato, F. Castellotti, M. Noro, Proceedings Conference "IIR International Conference (commercial refrigeration)", 137, (2005)

39. R. Lazzarin, F. Castellotti, Energy and Buildings 39, 59, (2007)

40. F. Busato, R. Lazzarin, M. Noro, Applied Thermal Engineering 31, 1648, (2011)

41. F. Busato, R. Lazzarin, M. Noro, Applied Thermal Engineering 57, 39, (2013)

42. R. Lazzarin, M. Noro, Energy and Buildings 174, 335, (2018)

43. M. Noro, R. Lazzarin, F. Busato, International Journal of Refrigeration 39, 104, (2014)

44. J. Bony, S. Citherlet, Energy and Buildings 39, 1065, (2007)

45. W. Streicher (edited by), Report C5 of Subtask C of IEA Solar Heating and Cooling programme - Task 32 - "Advanced storage concepts for solar and low energy buildings" (2008) 
46. F. Busato, R. Lazzarin, M. Noro, Proceedings "10th IIR Gustav Lorentzen Conference", ISBN 978-2-913149-90-8, (2012)

47. F. Busato, R. Lazzarin, M. Noro, Progettazione di un serbatoio di accumulo a cambiamento di fase (Designing of a PCM storage system in solar cooling) (in Italian), Report RdS/2012/125, ENEA, (2012)

48. R. Lazzarin, S. Mancin, M. Noro, G. Righetti, International Journal of Low Carbon Technologies 13(3), 286, (2018)

49. R. Lazzarin, M. Noro, G. Righetti, S. Mancin, Applied Sciences 9(5), 1007, (2019)

50. G. Righetti, R. Lazzarin, M. Noro, S. Mancin, International Journal of Refrigeration 106, 266, (2019)

51. M. Noro, S. Mancin, R. Lazzarin, G. Righetti, AiCARR Journal 63(4), 56, (2020) 